\title{
Bactérias gram-positivas problemas: resistência do estafilococo, do enterococo e do pneumococo aos antimicrobianos
}

\author{
Problem gram-positive bacteria: resistance in staphylococci, \\ enterococci, and pneumococci to antimicrobial drugs
}

\section{Walter Tavares}

\begin{abstract}
Resumo O autor faz uma revisão da resistência dos estafilococos, enterococos e pneumococos, enfocando os primeiros relatos, ocorrência mundial, mecanismos genéticos e bioquímicos da resistência, situação no Brasil e alternativas terapêuticas. Destaca os fatores envolvidos e contribuintes para a disseminação da resistência destas bactérias gram positivas problemas. Alerta para a importância da resistência na terapêutica das infecções por estes microrganismos e registra a necessidade de medidas para o seu controle.
\end{abstract}

Palavras-chaves: Resistência bacteriana. Bactérias gram-positivas. Estafilococos. Enterococos. Pneumococos.

Abstract The resistance in staphylococci, enterococci, and pneumococci is reviewed. The author also recalls the first cases, and presents an overview of the distribution of cases in the world, the genetic and molecular mechanisms of resistance, the importance in Brazil and therapeutic alternatives. The factors that contribute to the dissemination of these problem bacteria and the measures for their control are emphasized.

Key-words: Bacterial resistance. Gram-positive bacteria. Staphylococcus. Enterococcus. Pneumococcus.

O conhecimento do fenômeno da resistência a agentes físicos e químicos entre os microrganismos data do início da era microbiana. Com a introdução das primeiras substâncias químicas com finalidade quimioterápica específica, Ehrlich e seus colaboradores Franke e Roehl apud4, em 1905, descobriram o fenômeno da resistência às drogas, ao observarem que em culturas de tripanossomas africanos tratados com arsênico ou com determinados corantes havia a sobrevivência de alguns exemplares da mesma população microbiana. Estes autores descreveram que infecções por tripanossomas tratadas com doses baixas de arsenicais recaíam e relataram que um novo tratamento falhava porque os tripanossomas haviam desenvolvido resistência às drogas e que esta resistência passava a ser hereditária. O advento do uso clínico de sulfonamidas, em 1933, e, em seguida, da penicilina, em 1941, levou à constatação de que a resistência bacteriana aos agentes antimicrobianos podia ser uma característica natural das espécies de bactérias ou ser adquirida por cepas individuais dentro de uma população sensível.

Ao descobrir a penicilina em 1929, Fleming ${ }^{67}$ foi o primeiro observador da resistência natural de microrganismos aos antibióticos, descrevendo

Faculdade de Medicina de Teresópolis e Escola de Ciências Médicas de Volta Redonda, RJ.

Endereço para correspondência: Dr. Walter Tavares. Rua Oito de Dezembro 680/201, Vila Isabel, $20550-200$ Rio de Janeiro, RJ, Brasil. Telefax: 5521 569-7196.

Recebido para publicação em 6/10/99. 
que bactérias do grupo coli-tifóide e a Pseudomonas aeruginosa (Bacillus pyocyaneus) não eram inibidas pelo antibiótico. A causa desta resistência natural foi, pouco depois, descoberta por Abraham e Chain $^{1}$, que, em 1940, um ano antes da primeira publicação sobre o uso clínico da penicilina, demonstraram em extratos de E. coli uma enzima capaz de destruir a ação da penicilina, a qual denominaram penicilinase. A difusão do uso clínico da penicilina trouxe ao conhecimento o fato de que entre microrganismos sensíveis ao antibiótico havia o encontro de exemplares resistentes, sendo verificado por Kirby, em 1944, que alguns Staphylococcus aureus isolados de material clínico mostravam-se resistentes à penicilina devido à produção de penicilinase. Em 1946, nos Estados Unidos da América, cerca de $5 \%$ de estafilococos isolados de pacientes ou portadores eram resistentes à penicilina. Em 1949 esta resistência podia ser notada em $29 \%$ dos germes isolados em hospitais norte-americanos; em 1950 atingia $50 \%$ e em 1959 era de cerca de $80 \%{ }^{14}$. No Brasil, atualmente, acima de $80 \%$ dos $S$. aureus isolados de pacientes hospitalizados e cerca de $70 \%$ dos isolados de pacientes da comunidade apresentam resistência às penicilinas naturais e, por extensão, à ampicilina e amoxicilina ${ }^{58} 156158$

$\mathrm{Na}$ atualidade, a resistência bacteriana adquirida é descrita em praticamente todas as espécies de bactérias, conhecendo-se detalhes dos mecanismos de aquisição de resistência e os mecanismos moleculares da manifestação da resistência 45100101.

A resistência aos antimicrobianos é um fenômeno genético, relacionado à existência de genes contidos no microrganismo que codificam diferentes mecanismos bioquímicos que impedem a ação das drogas. A resistência pode ser originada em mutações que ocorrem no germe durante seu processo reprodutivo e resultam de erros de cópia na seqüência de bases que formam o ADN cromossômico, responsáveis pelo código genético. A outra origem da resistência é a importação dos genes causadores do fenômeno, consistindo na resistência transferível. Esta resistência faz-se através dos mecanismos de transdução, transformação e conjugação e, freqüentemente, envolve genes situados em plasmídios e transposons 45113114120132146177189200215 .

Em inúmeros microrganismos o fenômeno da resistência é natural. Em particular, a resistência é necessariamente específica contra um determinado antibiótico naqueles microrganismos produtores desta mesma substância. Assim, por exemplo, o Streptomyces erythraeus, produtor da eritromicina, é naturalmente resistente a este antibiótico por possuir uma estratégia de sobrevivência que impede sua auto-intoxicação. Esta estratégia consiste em possuir uma subunidade 50 S ribossomal à qual a eritromicina não se fixa, não exercendo, portanto, ação. Já os Streptomyces produtores de antibióticos aminoglicosídeos defendem-se da ação destes antibióticos em seus próprios ribossomas, por formarem enzimas que inativam internamente o antibiótico que eles mesmo produzem. Em outras bactérias e fungos produtores de antibióticos existem estes e outros mecanismos de autodefesa contra as substâncias que produzem, sendo estes mecanismos determinados geneticamente ${ }^{15} 4452$.

Considerando que os microrganismos produtores de antibióticos existentes no meio ambiente apresentam mecanismos de autoproteção codificados geneticamente, admite-se que, além da mutação, a origem da resistência adquirida em bactérias e fungos causadores de infecção no homem e outros mamíferos esteja principalmente relacionada à transferência de genes de resistência contidos nesses microrganismos presentes na natureza ${ }^{44} 52177$. Desta maneira, a existência de determinantes de resistência transferíveis entre os microrganismos precede ao emprego dos antibióticos na terapêutica. São indicativos deste fato, além dos exemplos já citados, o isolamento de exemplares de E. coli resistentes das fezes de pessoas vivendo em comunidades primitivas e que nunca receberam antibióticos; e a demonstração de genes de resistência em bactérias liofilizadas antes da introdução dos antibióticos ${ }^{50} 141177$.

A transferência de genes de resistência de bactérias não-patogênicas ou de baixa patogenicidade para microrganismos patogênicos provavelmente é um fenômeno comum. É possível, por exemplo, que a resistência do Bacteroides fragilis a tetraciclinas e eritromicina tenha origem, respectivamente, na Prevotella ruminicola e no Bacillus sphaericus. O primeiro é um anaeróbio do intestino de porcos e carneiros; o segundo é uma bactéria do solo ${ }^{64}$. Este fenômeno natural ganha importância, porém, com a utilização das substâncias antimicrobianas, por sua ação selecionadora de microrganismos resistentes. $O$ emprego das drogas antimicrobianas em seres humanos e animais possibilita a disseminação 
destes microrganismos, que é tanto maior quanto mais intenso for este uso. Casellas e Tome ${ }^{30}$ mencionam um exemplo recente deste fato. Em 1990 não existiam cepas de Klebsiella e estafilococos meticilina-resistentes com resistência à ciprofloxacina na Argentina e a maior parte das estirpes de $P$. aeruginosa e Acinetobacter era sensível a esta quinolona. Com o emprego caótico deste antimicrobiano em Buenos Aires, em $199830 \%$ das Klebsiella, 50\% das P.aeruginosa e estafilococos e $80 \%$ dos Acinetobactertornaramse altamente resistentes à ciprofloxacina. $\mathrm{Na}$ Islândia, Arason et $\mathrm{al}^{8}$ também observaram uma associação entre o uso de antimicrobianos, especialmente penicilinas, co-trimoxazol e eritromicina, e o encontro de pneumococos resistentes em crianças portadoras do germe no nasofaringe.

Embora existente, a resistência a drogas específicas nas bactérias causadoras de infecção humana era pouco freqüente ao início da era da antibioticoterapia. A importância do problema coincide com a introdução e a ampla utilização de inúmeros antimicrobianos na década de 1950, expandindo-se a partir de 1960, com a introdução dos novos antibióticos beta-lactâmicos, e agravando-se nas décadas de 1980 e 1990, com o surgimento de novas formas de resistência e a disseminação de germes multirresistentes. A importância das substâncias antimicrobianas no aumento do fenômeno da resistência reside no seu papel selecionador dos exemplares resistentes, através da pressão seletiva resultante de seu emprego clínico (humano e veterinário), industrial (conservação de alimentos), comercial (engorda de animais) e experimental|2563124177190208211. Sem dúvida, o uso clínico dos antimicrobianos exerce papel selecionador das estirpes resistentes e, provavelmente, é a principal causa da resistência, sobretudo a observada no ambiente hospitalar, onde o uso destas drogas é maior ${ }^{39}{ }^{191}$. Atualmente, se discute, inclusive, a possível ligação entre o uso de substâncias catiônicas biocidas, tais como clorexidina, amidinas, acridinas e derivados do amônio quaternário, e a seleção de bactérias resistentes a antimicrobianos ${ }^{171}$. A pressão seletiva do uso de antimicrobianos exerce papel fundamental na magnitude e disseminação da resistência, conforme bem conhecido no ambiente hospitalar e, mesmo, no meio extra-hospitalar. Exemplo desta última assertiva é o encontro de resistência ao cloranfenicol em 30 a $50 \%$ de isolamentos de $E$. coli na Indonésia, onde o cloranfenicol é utilizado largamente como droga de primeira escolha para o tratamento de diarréias. Ao contrário, nos Estados Unidos da América, onde o uso deste antibiótico é realizado com selecionado rigor, a resistência ao cloranfenicol é rara ${ }^{120}$.

A importância do uso de antimicrobianos em animais como elemento de influência no desenvolvimento de resistência microbiana tem sido motivo de discussão. Evangelisti et al62 concluíram não haver evidência de relação entre o uso de doses baixas de oxitetraciclina e o aumento de salmonelose em animais e o risco de resistência para seres humanos. Também Hayes et al ${ }^{86}$ referem não haver evidência científica relacionando o uso do glicopeptídeo avoparcina na alimentação de animais com a diminuição da eficácia da vancomicina em seres humanos. Apesar destas opiniões, esta não é a conclusão de outros autores, que valorizam a utilização de antimicrobianos na alimentação de animais, em especial o emprego de doses subterapêuticas visando a promoção rápida do crescimento e engorda dos animais, como um importante fator da disseminação da resistência para as bactérias patogênicas para o homem ${ }^{15} 5963$. Recentemente, Descheemaeker et a ${ }^{54}$, na Bélgica, estabeleceram alguma identidade de genes de resistência contra glicopeptídeos em Enterococcus faecium isolados em porcos e aves e no homem, indicando possibilidade de troca de marcadores genéticos de resistência entre animais e o homem. Também recentemente, Donnelly et $\mathrm{al}^{57}$ e Holzman ${ }^{93}$ discutem diversos aspectos da resistência dos enterococos à vancomicina em países da Europa e Américas, relacionando-a à utilização da avoparcina na alimentação de animais. O mesmo fenômeno vem sendo observado no México com as fluoroquinolonas, utilizadas neste país para promover o crescimento de animais ${ }^{93}$.

A resistência das diversas espécies bacterianas aos antimicrobianos é extremamente variável entre os países, regiões e a origem hospitalar ou comunitária das estirpes. Algumas espécies apresentam resistência amplamente difundida em todo o mundo, como é o caso do Staphylococcus aureus, enquanto que outras mantêm em todos os países notável sensibilidade às drogas ativas, como exemplificado pelo Streptococcus pyogenes e as penicilinas.

Dentre os microrganismos que sofreram grandes modificações na sensibilidade aos antimicrobianos com o correr dos anos, destacamse os estafilococos, as enterobactérias, a 
Pseudomonas aeruginosa, o Acinetobacter baumannii e, mais recentemente, os hemófilos, gonococos, enterococos e pneumococos. $\mathrm{Na}$ atualidade, é motivo de grande preocupação entre os cientistas, os microbiologistas e os médicos clínicos a resistência entre as bactérias gram-positivas, que vêm se tornando bactérias problemas na terapêutica antiinfecciosa.

Estafilococos. O isolamento de estafilococos resistentes às penicilinas pôde ser observado logo após os primeiros experimentos com a introdução da penicilina G na clínica em 1941, registrando-se em 1944 e 1945 índices de resistência de 12 a 22\% ${ }^{136}$. Em 1950, cerca de cinco anos após a disponibilidade deste antibiótico para o tratamento de infecções em populações civis, a resistência já atingia em torno de $30 \%$ das amostras hospitalares norteamericanas. Ao final da década de 1950, cerca de $80 \%$ dos estafilococos dourados isolados em hospitais americanos mostravam-se resistentes às penicilinas devido à produção de penicilinases inativadoras destas drogas, codificadas geneticamente em plasmídios transmissíveis por transdução ${ }^{14113164}$. Nos dias atuais, em praticamente todas as parte do Mundo, os estafilococos comunitários, sejam coagulase-positivo ou coagulase-negativo, mostram elevada resistência (acima de $70 \%$ ) à benzilpenicilina (penicilina G), bem como à penicilina $\mathrm{V}$, ampicilina, amoxicilina e carbenicilina ${ }^{136}$. Para combater estes estafilococos foram descobertas as penicilinas antiestafilocócicas, tais como a meticilina e a oxacilina e seus derivados, e as cefalosporinas da primeira e segunda gerações.

Contudo, logo após a introdução das primeiras penicilinas antiestafilocócicas, surgiram bactérias deste gênero resistentes a elas, inicialmente na Europa, em 1961, e depois em outras partes da Terra 2282114127136 . Na atualidade, estafilococos vêm mostrando crescente resistência também a estes beta-lactâmicos penicilinase-resistentes, registrando-se índices de resistência de 30\% a $66 \%$, notavelmente em hospitais de grande porte, com serviços de emergência aberto ao público e centros de referência para pacientes infectados ${ }^{136}{ }^{178}$. Nestes estafilococos, chamados MRSA ou ORSA (siglas em inglês indicando Staphylococcus aureus meticilina ou oxacilina resistentes) a resistência é resultado de genes cromossômicos que codificam modificações no receptor de ação dos beta-lactâmicos, as proteínas ligadoras de penicilinas (PBPs), havendo a produção de novas PBPs (PBP2' ou PBP 2a) com pequena afinidade pelos beta- lactâmicos. O surgimento destes genes de resistência possivelmente resultou de mutação e transposição entre os estafilococos. Menos freqüentemente, os estafilococos podem apresentar um nível baixo de resistência à oxacilina e à meticilina devido à produção de uma PBP estruturalmente modificada ou pela superprodução de beta-lactamases que inativam estes antibióticos 173569139202 . Deve-se notar que os MRSA são, igualmente, resistentes às cefalosporinas, embora possam haver discrepâncias na sensibilidade revelada ao antibiograma, e são também resistentes ao imipeném e outras carbapenemas. Da mesma maneira, estirpes de S. epidermidis, $S$. saprophyticus e $S$. haemolyticus, os estafilococos coagulasenegativos mais freqüentemente identificados na clínica, passaram a demonstrar resistência à oxacilina e substâncias afins. Freqüentemente, os estafilococos resistentes aos beta-lactâmicos penicilinase-resistentes (meticilina, oxacilina) mostram-se também resistentes a macrolídeos, aminoglicosídeos, tetraciclinas, mupirocina e cotrimoxazol por mecanismos bioquímicos específicos, codificados geneticamente no cromossoma ou em plasmídios 17224143113126127136139176195 . Ademais, é também crescente a resistência dos estafilococos às fluoroquinolonas ${ }^{106}$.

No Brasil, na atualidade, os estafilococos, tanto o S. aureus como o S. epidermidis, mostram-se resistentes à penicilina $\mathrm{G}$, ampicilina $\mathrm{e}$ amoxicilina em mais de $70 \%$ das cepas isoladas, seja em ambiente hospitalar ou na comunidade, não sendo mais indicado o uso destes antimicrobianos para o tratamento de infecções estafilocócicas, mesmo que benignas e mesmo que procedam do ambiente extra-hospitalar 58156158173176 . Além disto, estes germes vêm mostrando elevado índice de resistência à meticilina (portanto, também à oxacilina e cefalosporinas) no meio hospitalar no Brasil, repetindo-se o observado em outros países. Relatos de hospitais em diferentes regiões brasileiras encontram $30 \%$ a $100 \%$ do S. aureus resistentes à oxacilina 40173176183186195 . Esta situação da resistência à oxacilina varia com a região e, mesmo, o hospital analisado, devendo ser avaliada localmente. A título de exemplo, na mesma época (1988), na mesma cidade (Rio de Janeiro), a resistência à oxacilina foi de $27 \%$ entre as amostras de $S$. aureus isoladas no Hospital Gaffrée e Guinle (sem Serviço de Emergência), enquanto que no Hospital Souza Aguiar (com um dos maiores Serviços de Emergência da cidade) atingiu $58 \%{ }^{147^{150}}$. No 
entanto, estes microrganismos ainda mantêm boa sensibilidade (acima de $80 \%$ ) à oxacilina e cefalosporinas da primeira geração na maioria das cepas isoladas do meio extra-hospitalar no Brasil, possibilitando o uso destes antimicrobianos nas infecções estafilocócicas comunitárias ${ }^{47122133156 .}$ É necessário, porém, a contínua averiguação da sensibilidade destes patógenos, a fim de se determinar o aumento dos estafilococos meticilina-resistentes também na comunidade, fato este já referido em outros países. Com freqüência, o isolamento de estafilococos meticilina (oxacilina)-resistentes em pacientes no meio extra-hospitalar está relacionado ao uso prévio de antibióticos, internação recente, atendimento diário em centros médicos e uso de drogas ilícitas por via intravenosa ${ }^{46} 116$.

Afora raros isolamentos de estafilococos coagulase-negativos resistentes à vancomicina e/ou à teicoplanina109110136178 210 e do relato excepcional de estirpes de $S$. aureus resistentes à teicoplanina, mas com sensibilidade à vancomicina ${ }^{107210}$, os estafilococos mantiveram até recentemente a sensibilidade aos glicopeptídeos. Em 1996, porém, ocorreu o surgimento de estirpes de $S$. aureus com reduzida sensibilidade à vancomicina $(\mathrm{CIM}>8-16 \mathrm{mcg} / \mathrm{ml})$, inicialmente no Japão e a seguir nos Estados Unidos da América e agora em outras países 8889909194108109157168182185196. Estes estafilococos chamados inicialmente de VISA e GISA (siglas em inglês indicando Staphylococcus aureus (SA) com resistência intermediária à vancomicina ou aos glicopeptídeos), são atualmente denominados simplesmente de VRSA (Vancomicina Resistente SA) e encontramse em expansão em hospitais japoneses ${ }^{89}$. Seu mecanismo de resistência está relacionado a uma ativação da síntese da parede celular, havendo hiperprodução das proteínas ligadoras de penicilinas PBP2 e PBP2', espessamento da parede celular $\mathrm{o} o$ aprisionamento das drogas pela hiperprodução de componentes da parede ${ }^{8390205}$. Estafilococos com resistência aos glicopeptídeos foram recentemente encontrados também entre nós, registrando-se o isolamento de Staphylococcus aureus resistentes à vancomicina no Rio de Janeiro e estafilococos coagulase-negativos resistentes à vancomicina e/ou teicoplanina em São Paulo ${ }^{3150}$.

A resistência aos glicopeptídeos foi inicialmente observada em estafilococos que também mostravam resistência à meticilina e oxacilina e em pacientes submetidos anteriormente ao uso da vancomicina, o que indica a pressão de seleção de mutantes resistentes e não a transferência de genes de resistência do enterococo ${ }^{205}$. Os estafilococos resistentes aos glicopeptídeos têm como alternativas terapêuticas as estreptograminas (quinupristina/dalfopristina) e as oxazolidinonas (linezolid), recentemente disponíveis para uso clínico, e a combinação da vancomicina com um antibiótico beta-lactâmico antiestafilocócico 23138144172 . Novos compostos encontram-se em experimentação, incluindo substâncias das classes dos glicopeptídeos, everninomicinas e quinolonas ${ }^{37} 90$ 104. As estratégias para o controle dos estafilococos com resistência à vancomicina incluem as medidas universais de controle de infecção (luvas, cuidados com dejetos e secreções, lavagem das mãos), vigilância epidemiológica, isolamento, uso criterioso dos glicopeptídeos e tratamento dos pacientes infectados 33181206.

Enterococo. Os enterococos são habitantes da microbiota do trato digestivo humano e de outros animais, apresentando baixa patogenicidade. No entanto, são causa de infecções urinárias e intra-abdominais, endocardite e sepse, comportando-se, muitas vezes, como um agente oportunista em infecções hospitalares. Os enterococos podem ser causa de pelo menos $10 \%$ das infecções hospitalares e em algumas casuísticas situa-se em terceiro lugar como causa destas infecções, após Escherichia coli e Staphylococcus aureus. As principais espécies causadoras de infecção no homem são o Enterococcus faecalis e o Enterococcus faecium, que apresentam resistência natural a diversos antimicrobianos, incluindo aztreonam, co-trimoxazol, clindamicina e cefalosporinas. Habitualmente, têm pequena sensibilidade aos aminoglicosídeos e à penicilina $\mathrm{G}$, moderada sensibilidade à ampicilina e ao cloranfenicol, mas são bastante sensíveis aos glicopeptídeos. Cerca de 85 a $90 \%$ dos enterococos isolados na clínica são $E$. faecalis e 5 a $10 \%$ são $E$. faecium, sendo este último intrinsecamente mais resistente às penicilinas que o primeiro. Classicamente, as infecções enterocócicas são tratadas com a associação de ampicilina com gentamicina, considerando a ação sinérgica das drogas, devido à penetração dos aminoglicosídeos pela parede celular defeituosa causada pela ampicilina 97152163214 .

A resistência dos enterococos à ampicilina foi inicialmente descrita em 1983 por Murray e Mederski-Samoraj ${ }^{140}$ nos Estados Unidos da América, devendo-se à produção de beta- 
lactamases mediadas por plasmídios transferíveis. Posteriormente, foram descritas estirpes resistentes por modificações das proteínas ligadoras de penicilinas (PBPs), sobretudo no E. faecium, tornando-se freqüente o isolamento de enterococos ampicilina/aminoglicosídeo resistentes em infecções hospitalares ${ }^{51} 87148160$. Em hospitais norte-americanos, a resistência à gentamicina já atingia índices superiores a 50\% em 1987 e a resistência à ampicilina havia aumentado de $0,7 \%$ em 1987 para $8 \%$ em $1988^{18148214}$. Boyce et $\mathrm{al}^{18}$ consideram que o emprego do imipeném no seu hospital de trabalho possa ter contribuído para o elevado aumento de enterococos resistentes à ampicilina. No Brasil, Sader et al ${ }^{174}$ encontraram níveis elevados de resistência à gentamicina em $55 \%$ de 20 enterococos isolados de hemoculturas realizadas em 1997 em três laboratórios de referência. Nesta amostragem a resistência à ampicilina foi de $20 \%$. Deve-se considerar que o elevado nível de resistência dos enterococos à gentamicina neutraliza o efeito bactericida resultante da associação ampicilina/ gentamicina, diminuindo, portanto, a eficácia desta associação contra estes patógenos ${ }^{34} 160175$.

Em seguida, os enterococos passaram a demonstrar resistência também à vancomicina e outros glicopeptídeos, sendo registrados os primeiros casos a partir de 1986, no Reino Unido e na França, logo estendendo-se para outros países 117145203209 . Em 1989, a resistência à vancomicina era encontrada em $0,3 \%$ dos enterococos em hospitais norte-americanos ( $0,4 \%$ em UTI - Unidades de Tratamento Intensivo); em 1994, a resistência havia aumentado cerca de 35 vezes atingindo os índices de 10,4\% em enfermarias e 13,9\% em UTI e chegando a $25 \%$ em hospitais universitários em $1997^{75}$. Em países da Europa a resistência dos enterococos à vancomicina em geral é baixa, inferior a $10 \%$. A resistência aos glicopeptídeos é induzível e transferível, situando-se os genes de resistência no cromossoma, em plasmídios e em transposons. O mecanismo bioquímico desta resistência consiste em modificações na estrutura da parede celular, sendo observado que os enterococos com elevada resistência aos glicopeptídeos utilizam precursores do peptidoglicano alterados, codificados geneticamente, de tal modo que são produzidos precursores com terminação em $D$ alanil-D-lactato em lugar de D-alanil-D-alanina. Desta maneira, estes precursores modificados não são reconhecidos pela vancomicina e outros antibióticos do grupo 51128142209.
A resistência à vancomicina é dividida em baixo nível (resistência intermediária), quando a concentração inibitória mínima (CIM) situa-se entre 8 e $32 \mathrm{mcg} / \mathrm{ml}$, e alto nível (resistência elevada), quando a CIM é igual ou superior a $64 \mathrm{mcg} / \mathrm{ml}$. Esta resistência é comandada por genes denominados VanA, VanB, VanC , D, R, X e outros que agem diretamente ou controlam outros genes. Nos enterococos humanos, os mais importantes são os tipos genéticos VanA e VanB, o primeiro encontrado em cerca de $60 \%$ e o segundo em $40 \%$ dos enterococos resistentes isolados nos Estados Unidos da América ${ }^{97}$. $\mathrm{O}$ gene VanB, induzível, é localizado no cromossoma ou em transposons cromossômicos e é responsável pela resistência intermediária somente à vancomicina, mantendo a sensibilidade à teicoplanina. Os genes VanA são também induzíveis e localizam-se em transposons situados em plasmídios que eventualmente podem passar ao cromossoma, sendo responsáveis pela resistência elevada tanto à vancomicina como à teicoplanina. Os genes plasmidiais podem ser transferidos entre os enterococos humanos e de animais (E. gallinarum, E. casseliflavus, E. favium) e para outras bactérias gram-positivas (Listeria monocytogenes, Streptococcus sanguis), questionando-se se tais plasmídios poderão ser transmitidos para estafilococos 1860687077117135148162166169187210 . O gene VanC habitualmente é encontrado em enterococos de aves e o gene VanD foi observado em uma estirpe de E. faecium com elevada resistência à vancomicina e resistência intermediária à teicoplanina ${ }^{70}$. Na prática clínica, a maioria dos enterococos resistentes à vancomicina é do tipo VanA. Recentemente, Rice et al ${ }^{162}$ descreveram a transferência de resistência do tipo Van B mediada por plasmídios em estirpes de Enterococcus faecium originadas de pacientes hospitalizados, demonstrando a possibilidade da disseminação deste tipo de resistência.

Os genes de resistência aos glicopeptídeos nos enterococos provavelmente se originaram em microrganismos produtores desta classe de antimicrobianos, o Actinoplanes teichomyceticus e o Amycolatopsis orientalis, que são naturalmente resistentes aos antibióticos que produzem, respectivamente teicoplanina e vancomicina ${ }^{209}$. Tais genes de resistência foram transferidos para enterococos humanos e animais e estabeleceramse na medida em que ocorreu a pressão seletiva pelo aumento do emprego dos glicopeptídeos em medicina humana e veterinária e na engorda de 
animais. Especial preocupação reside no uso da avoparcina como aditivo alimentar para animais destinados à alimentação humana, podendo causar uma pressão seletiva de difícil controle para a emergência de resistência em enterococos que colonizam estes animais 54117128159210 . Em recente trabalho publicado em setembro de 1999, Stobberingh et al ${ }^{188}$, na Holanda, identificaram enterococos resistentes aos glicopeptídeos com as mesmas características genéticas em perus e em criadores e abatedores destas aves, concluindo que estes animais podem ser reservatórios e transmissores destes microrganismos para 0 homem.

Além da resistência aos beta-lactâmicos e aos glicopeptídeos, os enterococos adquiriram resistência elevada a outros antimicrobianos, por mutação ou transferência de plasmídios. Estes enterococos multirresistentes são também insensíveis ao cloranfenicol, tetraciclinas, eritromicina e rifampicina, variando seu isolamento com características locais ${ }^{70}$. As alternativas atuais para o tratamento de infecções por enterococos resistentes às penicilinas e glicopeptídeos são o cloranfenicol, a novobiocina (antibiótico em desuso), a eritromicina, tetraciclinas e ciprofloxacina, em associação entre si e com a gentamicina. A recente disponibilidade da quinupristina/dalfopristina e de oxazolidinonas constituem novas alternativas terapêuticas. Em particular, a associação quinupristina/dalfopristina vem revelando bons resultados no tratamento de infecções causadas pelo $E$. faecium, não tendo indicação nas infecções pelo E. faecalis 2233161117144172212 . Outras opções vêm sendo estudadas, incluindo a clinafloxacina, daptomicina, novas substâncias da classe dos glicopeptídeos e novos antimicrobianos como as glicilglicinas e everninomicinas 89104154163180210 . Além da terapêutica, medidas de controle dos enterococos resistentes devem ser colocadas em prática, incluindo a restrição ao uso de glicopeptídeos, o tratamento dos infectados e portadores, neste caso com a utilização por via oral de doxiciclina associada com rifampicina, isolamento de contato, além de vigilância epidemiológica e medidas universais de controle de microrganismos resistentes ${ }^{3253130181 .}$

No Brasil, a resistência dos enterococos é pouco conhecida, sendo referido por Caraccio et al ${ }^{28}$, em 1994, em um Hospital de Campinas, São Paulo, o isolamento de $E$. faecalis com resistência à ampicilina em 8,9\% das amostras, mas todos sensíveis à vancomicina. Também em 1994, Stern et $\mathrm{al}^{187}$, no Rio de Janeiro, estudando diferentes espécies de enterococos isolados de fontes humanas, animais e meio ambiente não encontraram amostras de $E$. faecalis resistentes à ampicilina, mas observaram $22,7 \%$ de resistência a este antibiótico no $E$. faecium, todos sensíveis à vancomicina. Ainda no Rio de Janeiro, Cardoso et al ${ }^{29}$, em 1996, estudando amostras de enterococos de origem comunitária e hospitalar, encontraram $15 \%$ de resistência para a gentamicina nas amostras comunitárias, não sendo detectada a resistência para a ampicilina e a vancomicina; nas amostras hospitalares verificaram $27 \%$ de resistência para a gentamicina e $8 \%$ para a ampicilina, sendo encontrada uma amostra de E. gallinarum resistente à vancomicina. Sader et $\mathrm{al}^{174}$, analisando amostras de enterococos originadas de diferentes cidades do país em 1997, relataram $20 \%$ de resistência para a penicilina G e $55 \%$ para a gentamicina, sendo todas as amostras sensíveis à vancomicina. Em 1998, em Uberlândia, Ribas e Gontijo Filho ${ }^{161}$, estudando enterococos isolados de material clínico, encontraram resistência de $31,7 \%$ à ampicilina e $70 \%$ à gentamicina. Não encontraram enterococos com nível de resistência elevado para a vancomicina, mas em duas de 60 amostras a resistência era intermediária, mantida a sensibilidade à teicoplanina.

Mais recentemente, amostras de enterococos com resistência aos glicopeptídeos passaram a ser relatadas também entre nós, sobretudo em São Paulo. Assim, Mimica et al ${ }^{134}$, em 1996, em hospitais universitários na capital de São Paulo, encontraram cerca de 3\% de Enterococcus sp. com resistência intermediária à vancomicina e sensibilidade à teicoplanina; em 1997, Cereda et $\mathrm{a}^{34}$, estudando 250 amostras de enterococos isolados durante os anos de 1994 e 1995 num hospital universitário na cidade de São Paulo, também encontraram $3,2 \%$ de enterococos (E. faecalis, E. gallinarum e E. casseliflavus) com resistência intermediária à vancomicina e alta sensibilidade à teicoplanina, característico do tipo VanB. Neste último trabalho, a resistência à ampicilina foi de $4,8 \%$ e à gentamicina foi de $26,4 \%$. Estudando as espécies principais, os autores verificaram que todas as amostras de $E$. faecium foram sensíveis à vancomicina, mas a resistência à ampicilina nesta espécie foi de $52 \%$, enquanto que todos os $E$. faecalis se mostraram sensíveis a esta penicilina. Ultimamente, a resistência à vancomicina e à teicoplanina foi também revelada no Brasil, com as descrições, inicialmente na cidade de Curitiba, em 1996, e depois em São Paulo, em 1997, de amostras de E. faecium 
multirresistente ${ }^{49212}$. Por fim, em 1998, ocorreu um surto de infecção e colonização por enterococos resistentes $(24,3 \%)$ à vancomicina e à teicoplanina em um hospital de grande porte na cidade de São Paulo, sendo identificados tanto o E. faecium como o E. faecalis 204213.

Pneumococo. A descoberta e a introdução da penicilina na terapêutica antimicrobiana provocou uma mudança no prognóstico das doenças infecciosas, particularmente notável em relação às infecções pneumocócicas. Na era pré-antibiótica a letalidade causada pela pneumonia pneumocócica era de cerca de $20 \%$, aumentando para $50 \%$ nos casos com sepse e para 80 a $100 \%$ na meningite pneumocócica. O emprego terapêutico da penicilina $\mathrm{G}$ (benzilpenicilina), fez estes índices caírem para 5\%, 20\% e 20-30\%, respectivamente ${ }^{199}$. Nos pacientes idosos, contudo, a mortalidade associada com infecção pneumocócica invasiva situa-se em $40 \%$ naqueles com idade superior a 85 anos, apesar da disponibilidade de terapêutica antibiótica específica e cuidados intensivos ${ }^{24}$. Por mais de 25 anos, a penicilina permaneceu a principal droga ativa contra o pneumococo, com eficácia inalterada nas citadas infecções e também nas sinusites, otites médias e bronquites bacterianas agudizadas. A sensibilidade do Streptococcus pneumoniae era elevada, sendo o germe inibido por concentrações iguais ou inferiores a $0,1 \mathrm{mcg} / \mathrm{ml}$ da penicilina. Do mesmo modo, o pneumococo permaneceu com sensibilidade aos macrolídeos, cloranfenicol e cefalosporinas.

Em 1967, foi notificado, na Austrália, o primeiro isolamento em material clínico de Streptococcus pneumoniae com resistência à penicilina, no escarro de uma paciente submetida a vários antimicrobianos. O pneumococo isolado apresentava resistência intermediária à penicilina $(\mathrm{CIM}=0,6 \mathrm{mcg} / \mathrm{ml})$ e mantinha a sensibilidade ao cloranfenicol, lincomicina e eritromicina ${ }^{84}$. Nos anos seguintes, novas amostras de pneumococo com resistência intermediária à penicilina foram isoladas na Papua-Nova Guiné, na Austrália e nos Estados Unidos da América, até que em 1977 pneumococos com elevada resistência à penicilina (CIM > $1 \mathrm{mcg} / \mathrm{ml}$ ) ocorreram de maneira epidêmica em hospitais na África do Sul. Diferentemente dos primeiros relatos, os pneumococos isolados na África do Sul mostravam resistência múltipla, não sendo também sensíveis ao cloranfenicol, tetraciclinas, eritromicina e clindamicina ${ }^{8599143}$. Desde então, o encontro de pneumococos com resistência intermediária e elevada à penicilina e a outros antimicrobianos passou a ser relatado em inúmeros outros países, inclusive no Brasil.
A resistência do Streptococcus pneumoniae à ação das penicilinas constitui na atualidade, ao final do século $X X$, problema grave em vários países, especialmente a África do Sul, Espanha, França, Estados Unidos da América, Coréia do Sul, Tailândia, Vietnã e países do leste europeu. O isolamento de estirpes resistentes é maior no ambiente hospitalar do que na comunidade; porém, descreve-se o encontro de $50 \%$ ou mais de amostras de pneumococo resistente isoladas de pacientes com infecções respiratórias ou meníngeas que chegam para atendimento médico naqueles países 610424856717998111123131199 . $\mathrm{Na}$ Coréia do Sul, $70 \%$ dos pneumococos isolados de diferentes materiais clínicos mostraram resistência à penicilina, dos quais $37 \% \mathrm{com}$ resistência intermediária e 33\% com elevada resistência ${ }^{119}$. No Egito, a resistência do pneumococo à penicilina foi encontrada em $22 \%$ a $29 \%$ das amostras isoladas em crianças com pneumonia, enquanto que na Grécia este padrão de resistência foi observado em $29 \%$ das amostras colhidas em crianças portadoras do germe no orofaringe ${ }^{149} 192$. Nestas últimas, $12 \%$ dos germes isolados apresentavam elevada resistência à penicilina $e$ mostravam também resistência elevada ao cloranfenicol, tetraciclinas e a outros antimicrobianos. Nos Estados Unidos da América a resistência do pneumococo era incomum até 1987, sendo registrada a resistência à penicilina em 1,8\% das amostras em 1979 e 3,6\% em 1987. Neste último ano, a resistência à eritromicina, tetraciclinas e co-trimoxazol era inferior a 3\%. Em 1994-1995, a resistência à penicilina do pneumococo em diferentes locais norte-americanos atingiu $23,6 \%$, isto é, 13 vezes maior que em 1979, e agora com resistência também a outros antimicrobianos ( $16 \%$ ou mais de resistência aos macrolídeos, co-trimoxazol, cefalosporinas) ${ }^{6}$. Na década de 1990, níveis também elevados de resistência em pneumococos foram encontrados em crianças portadoras na Bulgária (41,87\%), Eslováquia $(36,1 \%)$, Hungria $(70 \%)$ e Romênia $(92,9 \%)^{7129}$. Esta resistência à penicilina em geral foi acompanhada de resistência ao cloranfenicol, eritromicina e tetraciclinas. Na Hungria, a resistência à eritromicina subiu de $10 \%$ em 1976 para $32,8 \%$ em 1988 , o que é relacionado ao amplo uso deste antibiótico no país ${ }^{129}$. O mesmo fator aparentemente foi a causa do surgimento da resistência à penicilina, relacionada ao uso disseminado de apresentações de penicilina que conferem baixos níveis circulantes da droga para o tratamento da bouba e de infecções respiratórias na Papua-Nova Guiné26 36 . 
Também na Islândia, Arason et $\mathrm{a}^{8}$ observaram uma associação entre o uso de antimicrobianos, especialmente penicilinas, co-trimoxazol e eritromicina, e o encontro de pneumococos resistentes em crianças portadoras do germe no nasofaringe. Neste país, a resistência era desconhecida até 1989; em quatro anos, a multirresistência passou a ser observada em $20 \%$ das amostra isoladas ${ }^{42}$. Em contraste com esta distribuição da resistência, em outros países, como Inglaterra, Itália e Alemanha, os pneumococos permanecem em mais de $95 \%$ com sensibilidade à penicilina ${ }^{6}$. Também no Canadá a prevalência de pneumococos resistentes à penicilina é pequena $(7,3 \%$, com $1,9 \%$ de resistência elevada), porém vem aumentando nos últimos anos ${ }^{201}$. O mesmo ocorreu na Bélgica, onde a resistência aumentou de 2,3\% em 1993 para 7,6\% em 199492.

$A$ resistência à penicilina $G$ expressa, da mesma maneira, a resistência à ampicilina, à amoxicilina e às cefalosporinas da primeira geração.

Conceitualmente, se considera sensíveis à penicilina os pneumococos com CIM - $0,06 \mathrm{mcg} / \mathrm{ml}$; resistência intermediária $(\mathrm{RI})$ quando a CIM se situa entre $0,1 \mathrm{e} 1 \mathrm{mcg} / \mathrm{ml}$ e resistência elevada (RR) quando a CIM é $>1 \mathrm{mcg} / \mathrm{ml}^{26}$. Na grande maioria das vezes, os pneumococos resistentes à penicilina são os sorotipos 6, 14, 19 e $23^{19} 3680184199$. Freqüentemente, os pneumococos com elevada resistência à penicilina o são também a outros antimicrobianos, configurando o S. pneumoniae multirresistente ${ }^{111}$. Assim, nos Estados Unidos da América, nos anos 1994-1998 a resistência do pneumococo à penicilina era de 15 a 24\%, sendo elevada em $4 \%$ a 9,5\% das amostras; a resistência à eritromicina era de até $19 \%$; ao co-trimoxazol variava de $18 \%$ a $60 \%$; às fluoroquinolonas abaixo de $5 \%$, e era pequena a resistência ao cloranfenicol e às tetraciclinas $(4,5 \%$ e $7,3 \%$, respectivamente) e à clindamicina, por serem drogas pouco utilizadas naquele país ${ }^{19} 2655$. Na Espanha, a resistência à eritromicina dobrou no período de 1988 a 1992, passando de $7,6 \%$ para $15,2 \%{ }^{137}$. O aumento da resistência do Streptococcus pneumoniae aos macrolídeos e, por extensão, às lincosamidas e estreptograminas nos Estados Unidos da América é atribuída ao uso mais difundido dos macrolídeos para o tratamento, apropriado e inapropriado, de infecções respiratórias neste país 5 . Outros autores têm observado que a exposição prévia a uma determinada substância antimicrobiana pode predispor à infecção por pneumococos resistentes ao antimicrobiano usado ${ }^{111}$.
A resistência do pneumococo aos diversos antimicrobianos resulta de mecanismos específicos. A resistência à ação das penicilinas é mediada por genes cromossômicos que comandam alterações nas proteínas ligadoras de penicilinas, as PBPs 1a, 1b, 2x, 2a, 2b e 3, que passam a apresentar baixa afinidade de ligação com as penicilinas ${ }^{111} 184$. Estas PBPs alteradas apresentam também baixa afinidade para outros antibióticos beta-lactâmicos, mas, nos pneumococos com resistência intermediária, as cefalosporinas da segunda e da terceira gerações e as carbapenemas ainda têm afinidade de ligação e exercem ação antimicrobiana. Contudo, nas estirpes RR, que têm maior alteração nas PBPs $1 a, 2 b$ e 2x, ocorre elevada resistência também para as cefalosporinas e carbapenemas. Considerando que a resistência do $S$. pneumoniae não se deve à produção de beta-lactamases, a associação de inibidores destas enzimas a antibióticos beta-lactâmicos, como, por exemplo, a associação amoxicilina com ácido clavulânico, não oferece qualquer vantagem no combate às estirpes resistentes.

Originariamente, a resistência do pneumococo às penicilinas e outros beta-lactâmicos deve ser o resultado de mutações e progressiva seleção dos mutantes resistentes. No entanto, Crook e Spratt ${ }^{42}$ admitem a possibilidade de algum tipo de troca genética com estreptococos do grupo viridans (S. mitis, S. oralis), os quais podem apresentar resistência às penicilinas por um mecanismo similar ao dos pneumococos.

Em relação a outros antimicrobianos, a resistência à eritromicina é devida a modificação no ribossoma e presença de um sistema de efluxo, enquanto a resistência ao co-trimoxazol é resultante de modificações no metabolismo dos folatos, a resistência às tetraciclinas devese a um mecanismo de proteção do ribossoma e a do cloranfenicol à produção de uma acetiltransferase ${ }^{542} 165$.

Os pneumococos com elevada resistência às penicilinas freqüentemente mantêm a sensibilidade às fluoroquinolonas antipneumocócicas (levofloxacina, esparfloxacina, clinafloxacina e outras) e aos glicopeptídeos 121966 197. Desta maneira, estas drogas representam alternativas terapêuticas para infecções causadas por estas estirpes resistentes: as fluoroquinolonas para as infecções respiratórias e a vancomicina e a teicoplanina para as infecções sistêmicas. Em relação às meningoencefalites, o meropeném isoladamente mostrou-se sem atividade, 
enquanto que a associação da vancomicina com a ceftriaxona apresentou sinergismo ${ }^{74}$. Contudo, deve-se considerar que o uso associado de corticosteróides (dexametasona) no tratamento de meningite pode influenciar negativamente na concentração e na atividade da vancomicina no liquor $^{19}$. Por outro lado, recentemente, vêm sendo registradas estirpes de pneumococos que apresentam modificações de suas topoisomerases e apresentam um mecanismo de efluxo que as tornam resistentes também às novas fluoroquinolonas ${ }^{76} 153193$.

A resistência intermediária à penicilina não oferece dificuldade para o tratamento de infecções respiratórias ou sistêmicas pelo pneumococo, visto que as doses usuais ou em ligeiro excesso de penicilinas e cefalosporinas são adequadas para promover níveis superiores ao limite desta resistência. No entanto, a resistência intermediária pode influenciar na ação terapêutica das penicilinas nas meningites pneumocócicas, pois a concentração destas drogas não atinge o pneumococo RI quando está situado nas meninges. Nesta circunstância, as cefalosporinas da terceira geração mostram-se adequadas para o tratamento ${ }^{42}{ }^{194}$. O mesmo não acontece quando a meningite é causada por um pneumococo com elevada resistência, quando nem mesmo a ceftriaxona ou a cefotaxima exercem atividade terapêutica ${ }^{72}{ }^{102}$. Nesta situação, autores recomendam que o tratamento da meningite por pneumococos RR deve ser realizado com a vancomicina em associação com a ceftriaxona ou outra cefalosporina da terceira geração 61924111170 .

Desta maneira, nas regiões onde a freqüência do pneumococo resistente (seja com resistência intermediária ou elevada) à penicilina ultrapassar $10 \%$ recomenda-se, atualmente, nas infecções respiratórias o uso de fluoroquinolonas antipneumocócicas ou doses usuais de penicilinas (amoxicilina) ou cefalosporinas orais da segunda e terceira gerações (cefprozila, cefuroxima-axetil, cefixima). Se a resposta terapêutica for lenta ou se houver empiema, pode ser associada a rifampicina ao beta-lactâmico. Mesmo as sepses causadas por S. pneumoniae com elevada resistência habitualmente respondem à benzilpenicilina ou cefalosporinas por via intravenosa. Nos locais onde é raro o encontro de estirpes com elevada resistência, se houver comprometimento meníngeo, e o exame direto do liquor pelo método de Gram for sugestivo de Streptococcus pneumoniae, o tratamento inicial deve ser realizado com a ceftriaxona ou a cefotaxima, até que se tenha esclarecimento sobre a sensibilidade do pneumococo isolado. Nas regiões onde a presença dos pneumococos com elevada resistência ultrapassa $10 \%$, o tratamento inicial das meningites pneumocócicas deve ser realizado com a associação de vancomicina com uma cefalosporina da terceira geração (cefotaxima, ceftriaxona). Também foi proposto tratamento inicial com o emprego associado da vancomicina com rifampicina ou da ceftriaxona com rifampicina 13242627364273111 . A teicoplanina não é indicada na meningite pneumocócica por não atingir níveis adequados no liquor. A terapêutica das meningites pneumocócicas com o cloranfenicol isoladamente tem fracassado quando a cepa apresenta elevada resistência às penicilinas, por não ser atingida suficiente concentração bactericida no sistema nervoso ${ }^{7273}$. No entanto, é possível que a associação do cloranfenicol com a rifampicina possa ser útil nas meningites por pneumococos resistentes à penicilina e sensíveis ao cloranfenicol ${ }^{111}$.

Novas drogas encontram-se em lançamento ou em experimentação para o tratamento dos pneumococos multirresistente, entre as quais a quinupristina/dalfopristina e os compostos das classes dos cetolídeos, das everninomicinas, das glicilciclinas e das oxazolidinonas ${ }^{1123105118154 .}$

No Brasil, o isolamento de pneumococos com elevada resistência à penicilina é ainda pouco freqüente, mas vem aumentando nos últimos anos. Sessegolo et al ${ }^{179}$ encontraram $18 \%$ de amostras com resistência intermediária e $0,8 \%$ com resistência elevada em 288 amostras de pneumococos procedentes de diversas regiões do país no período 1988-1992. Das amostras com elevada resistência à penicilina 36\% e 29\% mostravam, também, elevada resistência às tetraciclinas e à associação sulfa-trimetoprima, respectivamente. No Rio de Janeiro, Duarte et al ${ }^{58}$ só encontraram uma cepa de pneumococo resistente à penicilina em 26 isolados a partir do sangue e secreções de pacientes no período 1991-1994. Mais recentemente, o estudo de Sader et $\mathrm{al}^{174}$, em 94 amostras do $S$. pneumoniae isoladas em 1997 em três laboratórios situados nas cidades de Florianópolis, Rio de Janeiro e São Paulo, revelou que $40,4 \%$ eram resistentes à penicilina, mas somente uma amostra $(1,1 \%)$ tinha elevada resistência. Em São Paulo, Berezin et al $^{16}$ estudaram 101 amostras de pneumococos isolados de crianças com doença 
invasiva admitidas no Hospital Emílio Ribas e na Santa Casa no período de 1989 a 1993; encontraram dez amostras $(9,8 \%)$ com resistência à penicilina, mas somente uma com resistência elevada ao antibiótico. Em estudo mais recente realizado por Rossi et al167 no Hospital do Câncer em São Paulo, de 50 amostras de $S$. pneumoniae isoladas em 1998-1999, uma (2\%) mostrou-se com elevada resistência e 12 (24\%) com resistência intermediária à penicilina. Também na cidade de São Paulo, Brandileone et $\mathrm{al}^{21}$, em 1998, analisaram 94 amostras de pneumococo isoladas de pacientes acima de 50 anos de idade infectados, não encontrando exemplares com elevada resistência, mas demonstrando a resistência intermediária em $7(7,4 \%)$ microrganismos. Em outro trabalho, também publicado em 1998, Brandileone et al ${ }^{20}$ apresentam os resultados do estudo de 1.252 amostras de $S$. pneumoniae originados de diferentes regiões do Brasil no período de 1993 a 1996, referindo a resistência média de $15,1 \%$, com $14,5 \%$ das amostras tendo resistência intermediária e somente $0,6 \%$ de elevada resistência à penicilina. Entre nós, o predomínio de pneumococos com elevada resistência à penicilina foi registrado em Salvador, Bahia, por Pinheiro et al ${ }^{155}$, os quais estudando 222 amostras de pneumococos isolados do liquor de pacientes com meningite no período de 12/95 a 10/98 identificaram $13 \%$ de amostras com elevada resistência à penicilina, pertencentes sobretudo aos sorotipos 14, 6B,19A e 19F. Estes resultados demonstram a necessidade de se realizar com regularidade a avaliação da sensibilidade destes microrganismos entre nós.

Considerações finais. Com exceção dos estafilococos, que desde o início da era antimicrobiana demonstraram a capacidade de resistir à ação dos antibióticos e quimioterápicos antiinfecciosos, o fenômeno da resistência bacteriana habitualmente era centrado nos bacilos gram-negativos. Tais microrganismos são freqüentemente envolvidos na gênese de infecções hospitalares e, por sua origem, também com freqüência apresentam selecionada sensibilidade aos antimicrobianos, muitas vezes mostrando padrões de resistência elevada e múltipla. O enterococo, por sua pequena patogenicidade, e o pneumococo, por causar infecção predominantemente extra-hospitalar, não eram motivo de preocupação entre os cientistas e profissionais da área da saúde, até porque mantinham um padrão de sensibilidade a antimicrobianos tradicionais. Mesmo o estafilococo, capaz de desenvolver mecanismos de resistência aos antibióticos beta-lactâmicos, encontrava na oxacilina e na vancomicina medicamentos adequados para o seu combate.

O panorama da relativa estabilidade dos cocos gram-positivos em relação à sensibilidade aos antimicrobianos é, agora, ao final do século XX, modificado, com a demonstração e expansão de estafilococos resistentes não só à oxacilina, mas também aos glicopeptídeos; de enterococos resistentes não só à ampicilina, mas também aos glicopeptídeos; e dos pneumococos resistentes às penicilinas e também às mais modernas cefalosporinas, mantendo, ainda, sensibilidade aos glicopeptídeos. E, se é verdade que a resistência dos estafilococos à vancomicina é atualmente um problema restrito às cepas hospitalares, o mesmo não ocorre com os enterococos e pneumococos que desenvolveram sua especial resistência no meio comunitário extra-hospitalar. Os estudos epidemiológicos e clínicos revelam que a resistência nestes microrganismos grampositivos encontra-se em ascensão e disseminação por todos os países. Não é de se estranhar este fato, com a facilidade de comunicação entre as diferentes regiões do planeta, os meios de transporte mais rápidos e o uso maciço de substâncias antimicrobianas com as mais diversas finalidades nestes tempos modernos.

Cabe, mais uma vez, uma reflexão sobre os caminhos da humanidade, envolvida com problemas primários de saneamento básico, anafalbetismo, desnutrição, mortalidade infantil, injúrias contra grupos minoritários, perseguições étnicas e religiosas, diferenças sociais alarmantes, extermínio de povos e culturas, guerras, drogas, violência, agressão ao meio ambiente. E é aqui, neste último contexto que surgem os microrganismos resistentes, entre os quais se inserem, agora, os controláveis cocos gram-positivos. Estes microrganismos são frutos do uso, do mal uso e, sobretudo, do abuso das substâncias antimicrobianas, num desvario sem precedentes e com as mais intoleráveis justificativas.

Germes resistentes habitam a face da Terra desde tempos imemoriais. Da mesma maneira, germes produtores de substâncias antimicrobianas sempre conviveram com microrganismos sensíveis a estas substâncias, em um equilíbrio ecológico da vida que mantinha cada um em seu nicho. A genial descoberta de Fleming abriu para a humanidade possibilidades de tratar e curar doenças, antes só percebidas por espíritos 
visionários. Doenças infecciosas que predominavam como causa de morbidade e mortalidade até a década de 1940, responsáveis pela maioria das internações em hospitais, passaram a ser tratadas etiologicamente pelos antimicrobianos, com isto modificando-se o seu prognóstico e reduzindose as internações por esta causa. Infelizmente, o próprio homem vem desbaratando esta conquista fantástica, com o uso irracional dos antibióticos e quimioterápicos antiinfecciosos. Após serem os antibióticos utilizados durante 50 anos, beneficiando a humanidade por diminuírem a ocorrência, a duração, as complicações e a letalidade das doenças infecciosas, especialmente das infecções bacterianas, chegamos ao final da década de 1990 com a evidência da capacidade dos microrganismos superarem a ação destas drogas. Continuam as infecções bacterianas a ameaçar a vida humana, causadas agora por microrganismos resistentes, e cada vez mais resistentes, e multirresistentes, levando à indagação sobre as perspectivas da era pósantibiótica, na qual infecções (quantas?) serão intratáveis ${ }^{38} 78105115125198$.

Uma comunicação da Organização Mundial da Saúde em 1996 estimou que dos 52 milhões de seres humanos mortos em $1995 \mathrm{em}$ mais de

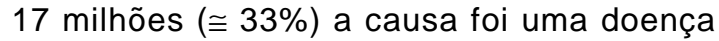
infecciosa. Destas, as infecções bacterianas

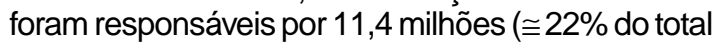
de mortes e $67 \%$ das mortes por infecções) ${ }^{125}$. Dentre as razões para esta elevada participação das infecções bacterianas entre as causas de morte do homem situa-se a crescente resistência destes microrganismos às substâncias antimicrobianas, denunciada nas incontáveis publicações sobre a disseminação de microrganismos resistentes em hospitais e sua ascensão no meio extra-hospitalar.

Se a resistência bacteriana é um fenômeno inevitável no espaço restrito do ambiente hospitalar, sua disseminação para o meio extrahospitalar deve merecer a análise, a crítica e o alerta de todos. Maiden ${ }^{125}$ considera que as discussões sobre a luta contra bactéria patogênicas obscurecem o fato que a evolução e a disseminação de microrganismos resistentes aos antibióticos são o resultado da pressão selecionadora imposta pelo homem. Neste sentido, situa-se não só a prescrição necessária destas drogas por médicos, dentistas e veterinários para situações clínicas que se beneficiam de seu emprego, como também o seu uso desnecessário nas situações inversas, o tratamento antimicrobiano sem diagnóstico estabelecido, a automedicação e a aquisição destes medicamentos em farmácias e drogarias sem qualquer tipo de controle, o desperdício de restos e de antimicrobianos com validade vencida no meio ambiente e o emprego destes fármacos como fatores de crescimento $e$ acréscimo de peso, na produção de alimentos animais. Com esta finalidade, deve ser considerado que não só os antimicrobianos utilizados em terapêutica humana podem exercer pressão seletiva de resistência, mas que outras substâncias colocadas em rações animais podem causar resistência cruzada com as drogas terapeuticamente úteis. São exemplos o emprego da avoparcina, podendo causar resistência à teicoplanina e à vancomicina, e o uso da virginiamicina, podendo causar resistência à quinupristina/dalfopristina, entre os enterococos ${ }^{125} 188$.

É necessário a Sociedade refletir sobre a importância, na disseminação de germes resistentes, do mal uso de antimicrobianos pelo médico, pelo dentista e pelo veterinário; da criminosa disponibilidade e venda destas substâncias sem qualquer tipo de controle; da autorização para a comercialização de produtos contendo substâncias antimicrobianas sem o rígido controle de qualidade; da insana aprovação para a engorda de animais de antimicrobianos usados na terapêutica ou a eles relacionados; da propaganda que tem por objetivo o lucro, sem a preocupação com aspectos éticos. É necessário discutir se a disseminação de microrganismos resistentes causando doenças no homem é o resultado da ignorância, da má administração, da má fé, da ganância. É dever da humanidade não permitir que as substâncias antimicrobianas colocadas à disposição do homem continuem desbaratadas e perdendo sua eficácia. É necessária a educação continuada dos profissionais da saúde para a prescrição e dispensação dos antimicrobianos e a educação da população sobre a sua utilidade. É necessário priorizar as medidas para controlar o seu uso mediante prescrição médica, assegurar a qualidade dos produtos comercializados e reduzir o seu uso na produção de alimento animal. É necessário um sistema de vigilância epidemiológica atuante, a valorização das comissões de controle de infecção hospitalar e laboratórios de microbiologia de qualidade. Nestas preocupações, associo-me a Baquero et al $^{10}$, Cohen ${ }^{38}$, Finch ${ }^{65}$, Goldmann e Huskins $^{78}$, Greenwood ${ }^{81}$, Holzman ${ }^{93}$, Hughes e Tenover ${ }^{95}$, Jones ${ }^{103}$; Kunin ${ }^{112}$; Maiden ${ }^{125}$; Pasternak ${ }^{151}$; Swartz ${ }^{191}$; Tomasz ${ }^{198}$; Wenzel e Edmond ${ }^{206}$; Williams e Heymann ${ }^{207}$, estudiosos que emitiram estas mesmas considerações. 
H.G.Wells, em seu clássico livro Guerra dos Mundos, escreveu, ao final, que quem acabou com os marcianos que haviam invadido a Terra foram as bactérias. Que este não seja um vaticínio para os próprios terráqueos, vítimas de exterminadores por eles mesmos construídos e selecionados.

\section{REFERÊNCIAS BIBLIOGRÁFICAS}

1. Abraham EP, Chain E. A enzyme from bacteria able to destroy penicillin. Nature 146:837, 1940.

2. Aeschlimann JR, Zervos MJ, Rybak MJ. Treatment of vancomycin-resistant Enterococcus faecium with RP 59500 (quinupristin-dalfopristin) administered by intermitent or continuous infusion, alone or in combination with doxycycline, in an in vitro pharmacodynamic infection model with simulated endocardial vegetations. Antimicrobial Agents and Chemotherapy 42:2710-2717, 1998.

3. Alamo LD, Cereda RF, Tosin I, Miranda EA, Machado AMO, Sader HS. Estudo da sensibilidade antimicrobiana de Staphylococcus coagulase negativa e caracterização de isolados com sensibilidade diminuída aos glicopeptídeos. Brazilian Journal of Infectious Diseases 3(supl 2):S24, 1999.

4. Albert A. Selective Toxicity. $4^{\text {th }}$ edition, Methuen Co, London, 1968.

5. Amsden GW. Pneumococcal macrolide resistance myth or reality. Journal of Antimicrobial and Chemotherapy 44:1-6, 1999.

6. Appelbaum PC. Epidemiology and in vitro suceptibility of drug-resistant Streptococcus pneumoniae. Pediatric Infectious Diseases Journal 15:932-939, 1996.

7. Appelbaum PC, Gladkova C, Hryniewicz W, Kojuharov B, Kotulova D, Mihalcu F, Schindler J, Setchanova L, Semina N, Trupl J, Tyski S, Urbaskova P, Jacobs MR. Carriage of antibiotic resistant Streptococcus pneumoniae in children in eastern and central Europe - a multicenter study with use of standardized methods. Clinical Infectious Diseases 23:712-717, 1996.

8. Arason VA, Dristinsson KG, Sigurdsson JA, Stefánsdóttir G, Mölstad S, Gudmundsson S. Do antimicrobials increase the carriage rate of penicillin resistant pneumococci in children? Cross sectional prevalence study. British Medical Journal 313:387-390, 1996.

9. Arthur M, Courvalin P. Genetics and mechanism of glycopeptide resistance in enterococci. Antimicrobial Agents and Chemotherapy 37:1563-1571, 1993.

10. Baquero $F$ and the Task Force of the General Direction for Health Planning of the Spanish Ministry of Health. Antibiotic resistance in Spain: what can be done? Clinical Infectious Diseases 23:819-823, 1996.

11. Barry AL, Fuchs PC, Brown SD. Antipneumococcal activities of a ketolide (HMR 3647), a streptogramin (quinupristin-dalfopristin), a macrolide (erythromycin), and a lincosamide (clindamycin). Antimicrobial Agents and Chemotherapy 42:945-946, 1998.

12. Barry, AL, Fuchs PC, Brown SD. In vitro activities of five fluoroquinolone compounds against strains of Streptococcus pneumoniae with resistance to other antimicrobial agents. Antimicrobial Agents and Chemotherapy 40:2431-2433, 1996.

13. Bartlet JG, Mundy LM. Community-acquired pneumonia. New England Journal of Medicine 333:1618-1623, 1995.

14. Bauer AW, Perry DM, Kirby WMM. Drug usage and antibiotic susceptibility of staphylococci. Journal of the American Medical Association 173:475-480, 1960.

15. Benveniste R, Davies J. Mechanism of antibiotic resistance in bacteria. Annual Review of Biochemistry 42:471-506, 1973.

16. Berezin EN, Carvalho ES, Casagrande S, Brandileone MCC, Mimica IM, Farhat CM. Streptococcus pneumoniae penicillin-nonsusceptible strains in invasive infections in São Paulo, Brazil. Pediatric Infectious Diseases Journal 15:1051-1053, 1996.

17. Boyce JM. Methicillin-resistant Staphylococcus aureus in Hospitals and long-term care facilities: microbiology, epidemiology and preventive measures. Infection Control and Hospital Epidemiology 13:725-737, 1992.

18. Boyce JM, Opal SM, Potter-Byone G, LaForge RG, Zervos MJ, Furtado G, Victor G, Medeiros A. Emergence and nosocomial trasmission of ampicillin resistant enterococci. Antimicrobial Agents and Chemotherapy 36:1032-1039, 1992.

19. Bradley JS, Scheld WM. The challenge of penicillinresistant Streptococcus pneumoniae meningitis: current antibiotic therapy in the 1990s. Clinical Infectious Diseases 24(supl 2):S213-S221, 1997.

20. Brandileone MCC, DiFábio JL, Vieira VSD, Zanella RC, Casagrande ST, Pignatari AC, Tomasz A. Geographic distribution of penicillin resistance of Streptococcus pneumoniae in Brazil: genetic relatedness. Microbial Drug Resistance. 4:209-217, 1998.

21. Brandileone MCC, Vieira VSD, Casagrande ST, Zanella RC, Guerra MLLS, Brandão AP, Melles CEAM, Pignatari AC, DiFabio JL, Austrian R. Characteristics of isolates of Streptococcus pneumoniae from middle aged and elderly adults in Brazil: capsular serotypes and antimicrobial sensitivity with invasive infections. Brazilian Journal of Infectious Diseases 2:90-96, 1998. 
22. Brumfitt W, Hamilton-Miller $\mathrm{H}$. Methicillin-resistant Staphylococcus aureus. New England Journal of Medicine 320:1188-1196, 1989.

23. Bryskier A. Novelties in the field of anti-infectives in 1997. Clinical Infectious Diseases 27:865-883, 1998.

24. Butler JC, Cetron MS. Pneumococcal drug resistance: the new "special enemy of old age". Clinical Infectious Diseases 28:730-735, 1999.

25. Buu-Hoi A, Goldstein FW, Acar JF. R-factors in grampositive and gram-negative aerobic bacteria selected by antimicrobial therapy. Scandinavian Journal of Infectious Diseases 49(supl):46-55, 1986.

26. Campbell Jr GD, Silberman R. Drug-resistant Streptococcus pneumoniae. Clinical Infectious Diseases 26: 1188-1195, 1998.

27. Cappelletty DM, Rybak MJ. Bactericidal activities of cefprozil, penicillin, cefaclor, cefixime, and loracarbef against penicillin-susceptible and -resistant Streptococcus pneumonia in an in vitro pharmacodynamic infection model. Antimicrobial Agents and Chemotherapy 40:1148-1152, 1996.

28. Caraccio MBB, Caiado CV, Bernal SBB, Falcão MJE. Microrganismos isolados em culturas em hospital secundário de 200 leitos de Campinas, SP. Revista da Sociedade Brasileira de Medicina Tropical 28(supl 1):263, 1995.

29. Cardoso FLL, Gazineo JLD, Teixeira LM, Alves EM, Bastos VLM, Ferreira RMC. Resistência a níveis elevados de aminoglicosídeos e resistência à ampicilina em amostras de enterococos isoladas de material clínico. In: Programa Científico do V Congresso Brasileiro de Controle de Infecção Hospitalar, Rio de Janeiro. Resumo no 163, p. 82, 1996.

30. Casellas JM, Tome G. Resistencia a los antibióticos: algo facil de lograr pero difícil de perder. Epidemiologia Y Vacunas (Buenos Aires - Laboratorio Elea) 2:1-6, 1998.

31. Cassell J, Balakrishnan I, Samarasinghe D, Mistry P, Prentice HG, Gillespie SH. RP59500 (Quinupristin/ dalfopristin): three case reports of its use in infection due to Enterococcus faecium. Journal of Infection 36: 324-327, 1998.

32. Centers for Diseases Control (CDC). Recommendations for preventing the spread of vancomycin resistance. Morbidity and Mortality Weekly Report 44(RR-12):1-13, 1995.

33. Centers for Diseases Control (CDC). Interim guidelines for prevention and control of staphylococcal infection associated with reduced susceptibility to vancomycin. Morbidity and Mortality Weekly Report 46:626-627, 1997,

34. Cereda R, Pignatari AC, Hashimoto A, Sader H. In vitro antimicrobial activity against Enterococci isolated in an Universitary Hospital in São Paulo, Brazil. Brazilian Journal of Infectious Diseases 1:83-90, 1997.

35. Chambers HF. Methicillin resistance in Staphylococci: molecular and biochemical basis and clinical implications. Clinical Microbiology Review 10:781-791, 1997.

36. Chesney PJ. The escalating problem of antimicrobial resistance in Streptococcus pneumoniae. American Journal Diseases of Children 146:912-916, 1992.

37. Climo MW, Patron RL, Archer GL. Combinations of vancomycin and $b$-lactams are synergistic against staphylococci with reduced susceptibilites to vancomycin. Antimicrobial Agents and Chemotherapy 43:1747-1753, 1999.

38. Cohen ML. Epidemiology of drug resistance: implications for a post-antibiotic era. Science 257:1050-1055, 1992.

39. Correa CMC, David CMN, Gontijo Filho PP. Uso de antimicrobianos e resistência bacteriana em um hospital universitário do Rio de Janeiro. Revista da Associação Médica Brasileira 35:46-48, 1989.

40. Costa JM, Ramos IB, Carvalho DG, Júnior RD. Análise da sensibilidade do Staphylococcus aureus hospitalar aos antimicrobianos no período 1988-1993. In: Programa Oficial e Resumos de Trabalhos do VIII Congresso Brasileiro de Infectologia, Porto Alegre. Resumo no 111, p. 87, 1994.

41. Coughter JP, Johnston L, Archer GL. Characterization of a staphylococcal trimethoprim resistance gene and its product. Antimicrobial Agents and Chemotherapy 31:1027-1032, 1987.

42. Crook DWM, Spratt BG. Multiple antibiotic resistance in Streptococcus pneumoniae. British Medical Bulletin 54:595-610, 1998.

43. Crossley K, Loesch D, Landesman B, Mead K, Chern $M$, Strate R. An outbreak of infections caused by strains of $S$. aureus resistant to methicillin and aminoglycosides. I. Clinical studies. Journal of Infectious Diseases 139:273-279, 1979.

44. Cundliffe E. Self defence in antibiotic-producing organisms. British Medical Bulletin 40: 61-67, 1984.

45. Cunha BA. Antibiotic resistance. Drugs of Today 34: 691-698, 1998.

46. Cushing R, Jui J, Levine DP, Chadzynski L, Nolan DC, Hayner NS (CDC). Community acquired methicillinresistant Staphylococcus aureus infections-Michigan. Morbidity and Mortality Weekly Report 30:185-186, 1981.

47. D' Azevedo PA, Kader ITA, Dias CAG. Staphylococcus aureus resistentes à oxacilina em estudantes de medicina da FFFCMPA. In: Programa Científico Oficial do VIII Congresso Brasileiro de Infectologia, Porto Alegre. Resumo no 139, p. 94, 1994. 
48. Dagan R, Yagupsky P, Goldbart A, Wasas A, Klugman $K$. Increasing prevalence of penicillin-resistant pneumococcal infections in children in southern Israel: implications for future immunization policies. Pediatric Infectious Diseases Journal 13:782-786, 1994.

49. Dalla Costa LM, Souza DC, Martins LTF, Zanella RC, Brandileone MC, Bokermann S, Sader HS, Souza APHM. Vancomycin-resistant Enterococcus faecium: first case in Brazil. Brazilian Journal of Infectious Diseases 2:160-163, 1998.

50. Davis $\mathrm{CH}$, Anandan J. The evolution of R factor. New England Journal of Medicine 282:117-122, 1970.

51. De Jonge BLM, Handweger S, Gage D. Altered peptidoglycan composition in vancomycin resistant Enterococcus faecalis. Antimicrobial Agents and Chemotherapy 40: 863-869, 1996.

52. Demain AL. How do antibiotic-producing microorganisms avoid suicide? Annals of New York Academy of Sciences 235:601-612, 1974.

53. Dembry LM, Uzowe K, Zervos MJ. Control of endemic glycopeptide-resistant enterococci. Infection Control and Hospital Epidemiology 17:286-292, 1996.

54. Descheemaeker PRM, Chapelle S, Devriese LA, Butaye P, Vandamme P, Goossens H. Comparison of glycopeptide-resistant Enterococcus faecium isolates and glycopeptide resistance genes of human and animal origins. Antimicrobial Agents and Chemotherapy 43:2032-2037, 1999.

55. Doern GV, Brueggemann A, Holley Jr P, Rauch AM. Antimicrobial resistance of Streptococcus pneumoniae from outpatients in the United States during the winter months of 1994 to 1995: results of a 30-center national surveillance study. Antimicrobial Agents and Chemotherapy 40:1208-1213, 1996.

56. Doit C, Loukil C, Fitoussi F, Geslin P, Bingen E. Emergence in France of multiple clones of clinical Streptococcus pneumoniae isolates with high-level resistance to amoxicillin. Antimicrobial Agents and Chemotherapy 43:1480-1483, 1999.

57. Donnelly JP, Voss A, Witte W, Murray BE. Does the use in animals of antimicrobial agents, including glycopeptide antibiotics, influence the efficacy of antimicrobial therapy in humans? Journal of Antimicrobial Chemotherapy 37:389-390, 1996.

58. Duarte D, Veras MA, Martins JA. Perfil evolutivo da resistência do Staphylococcus aureus - experiência do Hospital Adventista Silvestre. In: Programa Oficial e Resumo de Trabalhos do VIII Congresso Brasileiro de Infectologia, Porto Alegre. Resumo no 91, p. 82, 1994.

59. DuPont $\mathrm{H}$, Steele $\mathrm{JH}$. Use of antimicrobial agents in animal feeds: implication for human health. Review of Infectious Diseases 9:447-460, 1987.

60. Edmond MB, Ober JF, Weinbaum DL, Pfaller MA, Hwang T, Sanford MD, Wenzel RP. Vancomycin- resistant Enterococcus faecium bacteremia: risk factor for infection. Clinical Infectious Diseases 20:1126-1133, 1995.

61. Eliopoulos GM, Wennersten CB, Gold HS, Schülin T, Souli M, Farris MG, Cerwinka S, Nadler HL, Dowzicky M, Talbot GH, Moellering Jr. RC. Characterization of vancomycin-resistant Enterococcus faecium isolates from the United States and their suceptibility in vitro to dalfopristin quinupristin. Antimicrobial Agents and Chemotherapy 42:1088-1092, 1998.

62. Evangelisti DG, English, Girard AE, Lynch JE, Solomons IA. Influence of subtherapeutic levels of oxytetracycline on Salmonella typhimurium in swine, calves and chickens. Antimicrobial Agents and Chemotherapy 8:664-672, 1975.

63. Feinman SE. Antibiotics in animal feed - Drug resistance revisited. ASM News 64:24-30, 1998.

64. Ferber D. New hunt for the roots of resistance. Science 280:27, 1998.

65. Finch RG. Antibiotic resistance. Journal of Antimicrobial Chemotherapy 42:125-128, 1998.

66. Fitoussi F, Doit C, Benali K, Bonacorsi S, Geslin P, Bingen $\mathrm{E}$. Comparative in vitro killing activities of meropenem, imipenem, ceftriaxone, and ceftriaxona plus vancomycin at clinically achievable cerebrospinal fluid concentrations against penicillin-resistant Streptococcus pneumoniae isolates from children with meningitis. Antimicrobial Agents and Chemotherapy 42:942-944, 1998.

67. Fleming A. On the antibacterial action of cultures of a Penicillium, with special reference to their use in the isolation o $B$. influenzae. British Journal of Experimental Pathology 10: 226-236, 1929 (reimpressão Review of Infectious Diseases 2:129-139, 1980).

68. Fontana R. Overproduction of a low-affinity penicillinbinding protein and high-level ampicillin resistance in Enterococcus faecium. Antimicrobial Agents and Chemotherapy 38:1980-1983, 1994.

69. Franciolli M, Bille J, Glauser MP, Moreillon P. b-lactam resistance mechanisms of methicillin resistant Staphylococcus aureus. Journal of Infectious Diseases 163: 514- 523, 1991.

70. French GL. Enterococci and vancomycin resistance. Clinical Infectious Diseases 27(supl 1):S75-S83, 1998.

71. Friedland IR, Klugman KP. Antibiotic-resistant pneumococcal disease in South African children. American Journal Diseases of Children 146:920-923, 1992.

72. Friedland IR, Klugman KP. Failure of chloramphenicol therapy in penicillin-resistant pneumococcal meningitis. Lancet 339:405-408, 1992.

73. Friedland IR, McCracken Jr GH. Management of infections caused by antibiotic-resistant Streptococcus 
pneumoniae. New England Journal of Medicine 331:377-381, 1994

74. Friedland IR, Paris, M, Ehrett S, Hickey S, Olsen K, McCracken Jr, GH. Evaluation of antimicrobial regimens for treatment of experimental penicillin- and cephalosporin-resistant pneumococcal meningitis. Antimicrobial Agents and Chemotherapy 37:1630-1636, 1993.

75. Gaynes R, Edwards J, NNIS System. Nosocomial vancomycin resitant enterococci (VRE) in the United States, 1989-1995: the first 1000 isolates.Infection Control and Hospital Epidemiology 17(5-Part 2):18, 1996.

76. Gill MJ, Brenwald NP, Wise R. Identification of an efflux pump gene, pmrA, associated with fluoroquinolone resistance in Streptococcus pneumoniae. Antimicrobial Agents and Chemotherapy 43:187-189, 1999.

77. Goldmann DA. Vancomycin-resistant Enterococcus faecium: headline news. Infection Control and Hospital Epidemiology 13: 695-699, 1992.

78. Goldmann DA, Huskins WC. Control of nosocomial antimicrobial-resistant bacteria: a strategic priority for Hospitals worldwide. Clinical Infectious Diseases 24(supl 1): S139-S145, 1997.

79. Goldstein FW, Garau J. Resistant pneumococci: a renewed threat in respiratory infections. Scandinavian Journal of Infectious Diseases (supl 93):55-62, 1994.

80. Grebe T, Hakenbeck R. Penicillin-binding proteins $2 b$ and $2 x$ of Streptococcus pneumoniae are primary resistance determinants for different classes of b-lactam antibiotics. Antimicrobial Agents and Chemotherapy 40:829-834, 1996.

81. Greenwood D. Resistance to antimicrobial agents: a personal view. Journal of Medical Microbiology 47:751755, 1998.

82. Haley RW, Hightower AW, Khabbaz RF, Thornsberry C, Martone WJ, Allen JR, Hughes JM. The emergence of methicilin-resistant Staphylococcus aureus in United States hospitals. Annals of Internal Medicine 97:297308, 1982.

83. Hanaki H, Kuwahara-Arai K, Boyle-Vavra S, Daum RS, Labischinski $\mathrm{H}$, Hiramatsu K. Activated cell wall synthesis is associated with vancomycin resistance in methicillin-resistant Staphylococcus aureus clinical strains Mu3 and Mu50. Journal of Antimicrobial Chemotherapy 42:199-209, 1998.

84. Hansman D, Bullen MM. A resistant pneumococcus. Lancet 2:264-65, 1967.

85. Hansman D, Sturt J, Devitt L, Douglas R. Increased resistance to penicillin of pneumococci isolated from man. New England Journal of Medicine 284:175-177, 1971.

86. Hayes PW, Gustafson RH, Lotgering IFK, Mudd AJ. Does the use in animals of antimicrobial agents, including glycopeptide antibiotics, influence the efficacy of antimicrobial therapy in humans? Journal of Antimicrobial Chemotherapy 37:390-392, 1996.

87. Herman D, Gerding D. Antimicrobial resistance among enterococci. Antimicrobial Agents and Chemotherapy 35:1-4, 1991.

88. Himaratsu K (CDC). Reduced susceptibility of Staphylococcus aureus to vancomycin - Japan, 1996. Morbidity and Mortality Weekly Report 46:624-626, 1997.

89. Hiramatsu K, Aritaka N, Hanaki H, Kawasaki S, Hosoda Y, Hori S. Dissemination in Japanese hospitals of strains of Staphylococcus aureus heterogeneously resistant to vancomycin. Lancet 350:1670-1673, 1997.

90. Hiramatsu K, Hanaki H. Glycopeptide resistance in staphylococci. Current Opinion in Infectious Diseases 11:653-658, 1998.

91. Hiramastu K, Hanaki H, Ino T, Yabuta K, Oguri T, Tenover FC. Methicilin-resistant Staphylococcus aureus clinical strain with reduced vancomycin susceptibility. Journal of Antimicrobial Chemotherapy 40:135-136, 1997.

92. Hoefnagels-Schuemans A, Van Eldere J, Van Lierde $\mathrm{S}$, Verbist L, Verhaegen J, Peetermans WE. Increase in penicillin resistance rates in Belgium due to clonal spread of a penicillin-resistant 23F Streptococcus pneumoniae strain. European Journal of Clinical Microbiology and Infectious Diseases 18:120-125, 1999.

93. Holzman D. Despite insights, antibiotic resistance raises serious concerns. ASM News 64:317-319, 1998.

94. Howe RA, Bowker KE, Walsh TR, Feest TG, MacGowan AP. Vancomycin-resistant Staphylococcus aureus. Lancet 351:601-602, 1998.

95. Hughes JM, Tenover FC. Approaches to limiting emergence of antimicrobial resistance in bacteria in human populations. Clinical Infectious Diseases 24(suppl 1): S131-S135, 1997.

96. Husni R, Raad I. Treatment and prevention of vancomycin-resitant enterococcus. Current Opinion in Infectious Diseases 10:431-434, 1997.

97. Huycke MM, Sahm DF, Gilmore MS. Multiple-drug resistant Enterococci: the nature of the problem and an agenda for the future. Emerging Infectious Diseases 4: 239-249, 1998.

98. Jacobs MR. Increasing importance of antibioticresistant Streptococcus pneumoniae in acute otitis media. Pediatric Infectious Diseases Journal 15:940943, 1996.

99. Jacobs MR, Koornhof HJ, Robins-Browne RM, Stevenson CM, Freiman I, Witcomb M, Austrian, R. Emergence of multiply resistant pneumococci. New England Journal of Medicine 299:735-740, 1978. 
100. Jacoby GA. Epidemiology of extended-spectrum b-lactamases. Clinical Infectious Diseases 27:81-83, 1998.

101. Jacoby GA, Archer GL. New mechanisms of bacterial resistance to antimicrobial agents. New England Journal of Medicine 324: 601-612, 1991.

102. John CC. Traitment failure with use of third-generation cephalosporin for penicillin-resistant pneumococcal meningitis: case report and review. Clinical Infectious Diseases 18:188-193, 1994.

103. Jones RN. The emergent needs for basic research, education, and surveillance of antimicrobial resistance. Diagnostic Microbiology and Infectious Diseases 25:153-161, 1996.

104. Jones RN, Barrett MS. Antimicrobial activity of $\mathrm{SCH}$ 27899, oligosaccharide member of the everninomycin class with a wide gram-positive spectrum. Journal of Clinical Microbiology and Infection 1:35-43, 1995.

105. Jones RN, Pfaller MA. Bacterial resistance: a worldwide problem. Diagnostic Microbiology and Infectious Diseases 31:379-388, 1998.

106. Kaatz GW, Seo SM. Mechanisms of fluoroquinolone resistance in genetically related strains of Staphylococcus aureus. Antimicrobial Agents and Chemotherapy 41:2733-2737, 1997.

107. Kaatz GW, Seo SM, Dorman NJ, Lerner AS. Emergence of teicoplanin resistance during therapy of Staphylococcus aureus endocarditis. Journal of Infectious Diseases 162:103-108, 1990.

108. Krcméry Jr V, Hanzen J, Ciznar P, Brezaniova T. Vancomycin-resistant Staphylococcus aureus cellulitis in an immunocompromised child with Jobb's syndrome. Newsletter of International Society of Chemotherapy 1:5, 1997.

109. Krcméry Jr V, Trupl J, Drgona L, Lacka J, Kukuckova E, Oravcova E. Nosocomial bacteremia due to vancomycin-resistant Staphylococcus epidermidis in four patients with cancer, neutropenia and previous treatment with vancomycin. European Journal of Clinical Microbiology and Infectious Diseases 15:259263, 1996.

110. Krcméry Jr V, Trupl J, Spànik S. Bacteremia due to teicoplanin-resistant and vancomycin susceptible Staphylococcus haemolyticus in seven patients with acute leukemia and neutropenia receiving prophylaxis with ofloxacin. Infection 25:51-52, 1997.

111. Klugman KP. Pneumococcal resistance to antibiotics. Clinical Microbiological Reviews 3:171-196, 1990.

112. Kunin CM. Resistance to antimicrobial drugs - a worldwide calamity. Annals of Internal Medicine 118:557-561, 1993.

113. Lacey RW. Genetic basis, epidemiology and future significance of antibiotic resistance in Staphylococcus aureus. A review. Journal of Clinical Pathology 26:899-913, 1973.

114. Lacey RW. Antibiotic resistance in Staphylococcus aureus and streptococci. British Medical Bulletin 40:77-83, 1984.

115. Lambert HP. Impact of bacterial resistance to antibiotics on therapy. British Medical Bulletin 40:102-106, 1984.

116. Layton MC, Hierholzer Jr. WJ, Patterson JE. The evolving epidemiology of methicillin-resistant Staphylococcus aureus at a University Hospital. Infection Control and Hospital Epidemiology 16:12-17, 1995.

117. Leclercq R, Courvalin P. Resistance to glycopeptide in enterococci. Clinical Infectious Diseases 24:545-556, 1997.

118. Leclercq R, Courvalin P. Streptogramins: an answer to antibiotic resistance in gram-positive bacteria. Lancet 352:591-592, 1998.

119. Lee HJ, Park JY, Jang SH, Kim JH, Kim EC, Choi KW. High incidence of resistance to multiple antimicrobials in clinical isolates of Streptococcus pneumoniae from a University Hospital in Korea. Clinical Infectious Diseases 20:826-835, 1995.

120. Levy SB. Microbial resistance to antibiotics. Lancet 2:83-88, 1982.

121. Lima LC. Mecanismos bioquímicos de resistência aos antibióticos. Instituto de Microbiologia da UFRJ. Anais de Microbiologia XVI:53-57, 1969.

122. Lima MPJS, Rocha MDC, Xavier VLF, Sofiato VA, Filho EM. Avaliação do perfil do $S$. aureus encontrado na comunidade $\mathrm{x}$ infecção hospitalar. In: Programa Científico Oficial do VIII Congresso Brasileiro de Infectologia, Porto Alegre. Resumo no 68, p. 76, 1994.

123. Liñares J, Alonso T, Pérez JL, Ayaats J, Domínguez MA, Pallarés R, Martín R. Decreased susceptibility of penicillin-resistant pneumococci to twenty-four b-lactam antibiotics. Journal of Antimicrobial and Chemotherapy 30:279-288, 1992.

124. Linton $\mathrm{AH}$. Antibiotic-resistant bacteria in animal husbandry. British Medical Bulletin 40:91-95, 1984.

125. Maiden MCJ. Horizontal genetic exchange, evolution, and spread of antibiotic resistance in bacteria. Clinical Infectious Diseases 27(supl 1): S12-S20, 1998.

126. Malouin F, Bryan LE. Modification of penicillin-binding proteins as mechanisms of B-lactam resistance. Antimicrobial Agents and Chemotherapy 30:1-5, 1986.

127. Maple PAC, Hamilton-Miller JMT, Brumfitt W. Worldwide antibiotic resistance in methicillin-resistant Staphylococcus aureus. Lancet 1:537-540, 1989.

128. Marshall CG, Lessard LAD, Park LS, Wright GD. Glycopeptide antibiotic resistance genes in glycopeptide-producing organisms. Antimicrobial Agents and Chemotherapy 42:2215-2220, 1998. 
129. Marton A, Gulyas M, Munoz R, Tomasz A. Extremely high incidence of antibiotic resistance in clinical isolates of Streptococcus pneumoniae in Hungary. Journal of Infectious Diseases 163:542-548, 1991.

130. Mayall CG. Prevention and control of vancomycin resistance in gram-positive coccal microrganisms: fire prevention and fire fighting. Infection Control and Hospital Epidemiology 17:353-355, 1996.

131. McCracken Jr GH. Recent perspectives on drugresistant Streptococcus pneumoniae: Introduction. Pediatric Infectious Diseases Journal 15:930-931, 1996.

132. McDonald S. Transduction of antibiotic resistance in Staphylococcus aureus. Lancet 2:1107, 1966.

133. Mello MJG, Magalhães V, Coelho MFC, Vasconcelos MAP. Etiologia e perfil de sensibilidade aos antimicrobianos das infecções comunitárias em crianças hospitalizadas. In: Programa Científico Oficial do IX Congresso Brasileiro de Infectologia, Recife. Resumo no 210, p. 132, 1996.

134. Mimica I, Mendes CM, Mimica L, Oplustil C, Pignatari AC, Sader H. Estudo da sensibilidade de Staphylococcus sp e Enterococcus sp à teicoplanina e à vancomicina. Revista da Associação Médica Brasileira 42:147-150, 1996

135. Montecalvo MA, Horowitz H, Gedris C, Carbonaro C, Tenover FC, Issah A, Cook P, Wormser GP. Outbreak of vancomycin, ampicillin, and aminoglycoside-resistant Enterococcus faecium bacteremia in an adult oncology unit. Antimicrobial Agents and Chemotherapy 38:13631367, 1994.

136. Moreira BM, Daum RS. Antimicrobial resistance in staphylococci. Pediatric Clinics of North America 42:619-648, 1995.

137. Moreno S, García-Leoni ME, Cercenado E, Diaz MD, Quiróz JCLB, Bouza, E. Infections caused by erythromycin-resistant Streptococcus pneumoniae: incidence, risk factors, and response to therapy in a prospective study. Clinical Infectious Diseases 20:11951200, 1995.

138. Mulazimoglu L, Drenning SD, Yu V. In vitro activities of two novel oxazolidinones (U100592 and U100766), a new fluoroquinolone (trovafloxacin), and dalfopristinquinupristin against Staphylococcus aureus and Staphylococcus epidermidis. Antimicrobial Agents and Chemotherapy 40:2428-2430, 1996.

139. Mulligan ME, Murray-Leisure KA, Ribner BS, Standiford HC, John JF, Korvick JA, Kauffman CA. Methicillinresistant Staphylococcus aureus: a consensus review of the microbiology, pathogenesis and epidemiology with implications for prevention and management. American Journal of Medicine 94:313-328, 1993.

140. Murray BE, Mederski-Samoraj BD. Transferable betalactamase: a new mechanism for in vitro penicillin resistance in Streptococcus faecalis. Journal of Clinical Investigation 72:1168-1171, 1983.

141. Murray BE, Moellering Jr RC. Patterns and mechanisms of antibiotic resistance. Medical Clinics of North America 62:899-923, 1978.

142. Nagajaran R. Antibacterial activities and mode of action of vancomycin and related glycopeptides. Antimicrobial Agents and Chemotherapy 35:605-609, 1991.

143. Naraqi S, Kirkpatrick GP, Kabins S. Relapsing pneumococcal meningitis: isolation of an organism with decreased susceptibility to penicillin G. Journal of Pediatrics 85:671-673, 1974.

144. Noskin GA, Siddiqui F, Stosor V, Kruzynski J, Peterson LR. Successful treatment of persistent vancomycinresistant Enterococcus faecium bacteremia with linezoli and gentamicin. Clinical Infectious Diseases 28:689690, 1999.

145. Noskin GA, Stosor V, Cooper I, Peterson LR. Recovery of vancomycin-resistant enterococci on fingeretips and environmental surfaces. Infection Control and Hospital Epidemiology 16:577-581, 1995.

146. Novick R. Plasmids. Scientific American 24:77-90, 1980.

147. Oliveira ALC, Damasco PV, Melino TL, Souza DC, Oliveira VM, Pinto AM, Solari CA, Frajhot L, Fioravanti FA, Klôh MI. Prevalência de MRSA em um Hospital Universitário do RJ. Revista da Sociedade Brasileira de Medicina Tropical 32(supl 1):432, 1999.

148. Oster SE, Chirurgi VA, Goldberg AA, Aiken S, McCabe RE. Ampicillin-resistant enterococcal species in an acute-care-hospital. Antimicrobial Agents and Chemotherapy 34:1821-1823, 1990.

149. Ostroff SM, Harrison LH, Khallaf N, Assaad MT, Guirguiss NI, Harrington S, El-Alamy M. Resistance patterns of Streptococcus pneumoniae and Haemophilus influenzae isolates recovered in Egypt from children with pneumonia. Clinical Infectious Diseases 23:10691074, 1996.

150. Otília Santos HLR, Patrícia Pinheiro YM, Miguel R, Cyranka Y. Perfil de sensibilidade do Staphylococcus aureus e Staphylococcus epidermidis no Hospital Municipal Souza Aguiar, 1ํsemestre de 1998. Revista da Sociedade Brasileira de Medicina Tropical 32(supl 1):423, 1999.

151. Pasternak J. Abuso de antibióticos: um retrato da realidade. Revista da Associação Médica Brasileira 32:110, 1986.

152. Perry JD, Jones AL, Gould FK. Glycopeptide tolerance in bacteria causing endocarditis. Journal of Antimicrobial Chemotherapy 44:121-124, 1999.

153. Pestova E, Beyer R, Cianciotto NP, Noskin GA, Peterson LR. Contribution of topoisomerase IV and DNA gyrase mutations in Streptococcus pneumoniae 
to resistance to novel fluoroquinolones. Antimicrobial Agents and Chemotherapy 43:2000-2004, 1999.

154. Petersen PJ, Jacobus NV, Weiss WJ, Sum PE, Testa $\mathrm{RT}$. In vitro and in vivo antibacterial activities of a novel glycylcycline, the 9-t-butylglycylamido derivative of minocycline (GAR-936). Antimicrobial Agents and Chemotherapy 43:738-744, 1999.

155. Pinheiro RM, Gouveia EL, Lôbo TS, Cordeiro SM, Reis JN, Salgado K, Dourado CR, Tavares Neto J, Rocha H, Johnson WR, Riley LW, Reis MG, Ko AI. Vigilância ativa para Streptococcus pneumoniae não-sensíveis a penicilina em Salvador, Bahia. Revista da Socidade Brasileira de Medicina Tropical 32(supl 1):149-150, 1999.

156. Pinto CAG, Santi LQ, Santos AAM, Souza APG, Melo V, Belmok TTA, Silva EB, Roesberg JAQ, Deschamps AVM, Pena PM, Pereira ID, Ochua D. Comportamento microbiológico das infecções comunitárias no Hospital Municipal Odilon Behrens (HNOB) - jan/94 a dez/95. In: Programa Científico Oficial do IX Congresso Brasileiro de Infectologia, Recife. Resumo nํ413, p. 184, 1996.

157. Ploy MC, Grelaud C, Martin C, De Lumley L, Denis F. First clinical isolate of vancomycin-intermediate Staphylococcus aureus in a French hospital. Lancet 351:1212, 1998.

158. Rangel E, Furtado, A, Furtado W, Macedo J, Cunha Jr. AC, Macedo V, Moretto D. Avaliação das culturas de secreções do laboratório do Hospital Universitário de Brasília (HUB)-DF e do perfil de resistência aos antimicrobianos, de outubro/93 a março/94. Revista da Sociedade Brasileira de Medicina Tropical 28(supl 1):263, 1995.

159. Reynolds PE. Glycopeptide resistance in gram-positive bacteria. Journal of Medical Microbiology 35:14-17, 1992.

160. Rhinehart E, Smith NE, Wennersten C, Gorss E, Freeman J, Eliopoulos GM Moellering Jr. RC, Goldmann DA. Rapid dissemination of b-lactamaseproducing aminoglycoside-resistant Enterococcus faecalis among patients and staff on an infant-toddler surgical ward. New England Journal of Medicine 323:1814-1817, 1990.

161. Ribas RM, Gontijo Filho PP. Avaliação da presença de Enterococcus (ENT) resistente à vancomicina (VAN) em pacientes internados no Hospital de Clínicas da Universidade Federal de Uberlândia. In: Resumos do VI Congresso Brasileiro de Controle de Infecção e Epidemiologia Hospitalar, Campos do Jordão. Poster ํㅡ 58, p. 149. 1998.

162. Rice LB, Carias LL, Donsey CL, Rudin SD. Transferable plasmid-mediated VanB-type glycopeptide resistance in Enterococcus faecium. Antimicrobial Agents and Chemotherapy 42:963-964, 1998.
163. Rice LB, Shlaes DM. Vancomycin resistance in the enterococcus. Pediatric Clinics of North America 42:601-618, 1995.

164. Richmond $\mathrm{MH}$. Dominance of the inducible state in strains of Staphylococcus aureus containing two distinct penicillinase plasmids. Journal of Bacteriology 90: 370 374, 1965.

165. Robins-Brown RM, Gaspar MN, Ward JI, Wachsmuth IK, Koornhof HJ, Jacobs MR, Thornsberry C. Resistance mechanisms of multiply resistant pneumococci. Antimicrobial Agents and Chemotherapy 15:470-474, 1979.

166. Rosato A, Pierre J, Billot-Klein D, Buu-Hoi A, Gutmann L. Inducible and constitutive expression of resistance to glycopeptide and vancomycin dependence in glycopeptide-resistant Enterococcus avium. Antimicrobial Agents and Chemotherapy 39:830-833, 1995.

167. Rossi F, Vozza Jr JA, Mangini C, Lotfi C. Análise do perfil de sensibilidade do Streptococcus pneumoniae. Brazilian Journal of Infectious Diseases 3(supl 2):S103, 1999.

168. Rotun SS, McMath V, Schoonmaker DJ, Maupin PS, Tenover FC, Hill BC, Ackman DM. Staphylococcus aureus with reduced susceptibility to vancomycin isolated from a patient with fatal bacteremia. Emerging Infectious Diseases 5:147-149,1999.

169. Rubin LG, Tucci V, Cercenado E, Eliopoulos G, Isenberg HD. Vancomycin-resistant Enterococcus faecium in hospitalized children. Infection Control and Hospital Epidemiology 13:700-704, 1992.

170. Rubinstein E, Rubinovitch B. Treatment of severe infections caused by penicillin-resistant pneumococci. Role of third generation cephalosporins. Infection 22(supl 3):S161-S166, 1994.

171. Russell AD, Tattawasart U, Maillard JY, Furr JR. Possible link between bacterial resistance and use of antibiotics biocides. Antimicrobial Agens and Chemotherapy 42:2151, 1998.

172. Rybak MJ, Cappelletty DM, Moldovan T, Aeschlimann JR, Kaatz GW. Comparative in vitro acitivities and postantibiotic effects of the oxazolidinone compounds eperezolid (PNU-100592) and linezolid (PNU-100766) versus vancomycin against Staphylococcus aureus, coagulase-negative staphylococci, Enterococcus faecalis, and Enterococcus faecium. Antimicrobial Agents and Chemotherapy 42:721-724, 1998.

173. Sader H. Resistência bacteriana. Fascículo 1. Laboratórios Pfizer, São Paulo, 1998.

174. Sader HS, Sampaio JLM, Zoccoli C, Jones RN. Results of the 1997 SENTRY antimicrobial surveillance program in three brazilian medical centers. Brazilian Journal of Infectious Diseases 3:63-79, 1999.

175. Saham DF, Gilmore MS. Transferability and genetic relatedness of high-level gentamicin resistance among 
enterococci. Antimicrobial Agents and Chemotherapy 38:1194-1196, 1994.

176. Santos Filho L, Freitas FIS, Siqueira Jr JP. Evolution of drug-resistance in Staphylococcus aureus from a brazilian university hospital. Folha Medica (Br) 108:101103, 1994.

177. Saunders JR. Genetics and evolution of antibiotic resistance. British Medical Bulletin 40:54-60, 1984.

178. Schwalbe RS, Stapleton JT, Gilligan PH. Emergence of vancomycin resistance in coagulase-negative staphylococci. New England Journal of Medicine 316:927-930, 1987

179. Sessegolo JF, Levin AS, Levy CE, Asensi M, Fackam RR, Teixeira LM. Distribution of serotypes and antimicrobial resistance of Streptococcus pneumoniae strains isolated in Brazil from 1988 to 1992. Journal of Clinical Microbiology 32:906-911, 1994.

180. Shlaes DM, Al-Obeid S, Shlaes JH, Williamson R. Activity of various glycopeptides against an inducibly vancomycin-resistant strain of Enterococcus faecium. Journal of Infectious Diseases 159:1132-1135, 1989.

181. Shlaes DM, Gerding DN, John Jr JF, Craig WA, Bornstein DL, Duncan RA, Eckman MR, Farrer WE, Greene WH, Lorian V, Levy S, mcgowan Jr. JE, Paul SM, Ruskin J, Tenover FC, Watanakunakorn C. Society of Healthcare Epidemiology of America and Infectious Diseases Society of America Joint Committe on the Prevention of Antimicrobial Resistance. Guidelines for the prevention of antimicrobial resistance in hospitals. Clinical Infectious Diseases 25:584-599, 1997.

182. Sieradzki K, Roberts RB, Haber, SW, Tomasz A. The development of vancomycin resistance in a patient with methicillin resistant Staphylococcus aureus infection. New England Journal of Medicine 340:517-523, 1999.

183. Silva Neto RS, Figueiredo SM, Nunes MRCM, Veras $\mathrm{KN}$. Estudo de microrganismos multirresistentes , segundo antibióticos-índice, no Hospital Getúlio Vargas, de agosto de 1996 a abril de 1998 - Teresina, $\mathrm{Pi}$. Brazilian Journal of Infectious Diseases 3(supl 2):S80, 1999.

184. Smith A, Klugman KP. Alterations in PBP $1 \mathrm{~A}$ essential for high-level penicillin resistance in Streptococcus pneumoniae. Antimicrobial Agents and Chemotherapy 42:1329-1333, 1998.

185. Smith TL, Pearson ML, Wilcox, KR, Cruz C, Lancaster MV, Robinson-Dunn B, Tenover FC, Zervos MJ, Band JD, White E, Jarvis WR. Emergence of vancomycin resistance in Staphylococcus aureus. New England Journal of Medicine 340:493-501, 1999.

186. Souza KMC, Oliveira LA, Ribeiro EL. Susceptibilidade antimicrobiana em um Hospital Universitário. Revista da Sociedade Brasileira de Medicina Tropical 31(supl 1):205, 1998 .
187. Stern CS, Carvalho MGS, Teixeira LM. Characterization of enterococci isolated from human and nonhuman sources in Brazil. Diagnostic Microbiology and Infectious Diseases 20:61-67, 1994.

188. Stobberingh E, van den Bogaard A, London N, Driessen C, Top J, Willems R. Enterococci with glycopeptide resistance in trukeys, turkey farmers, turkey slaughteres, and (sub)urban residents in the south of The Netherlands: evidence for transmission of vancomycin resistance from animals to humans? Antimicrobial Agents and Chemotherapy 43:2215-2221, 1999.

189. Suassuna I. Noções gerais e incidência da resistência bacteriana. In:Gomes AJ (Ed.) Simpósio Internacional sobre Resistência Bacteriana e Infecções Mistas, São Paulo, 1982. Anais. São Paulo, Unipress, 1983.

190. Suassuna I, Suassuna IR. Perspectivas do emprego clínico dos antibióticos. Tribuna Médica 14:10-17, 1971.

191. Swartz MN. Use of antimicrobial agents and drug resistance. New England Journal of Medicine 337:491492, 1997.

192. Syrogiannopoulos GA, Grivea IN, Beratis NG, Spiliopoulou AE, Fasola EL, Bajaksouzian S, Appelbaum PC, Jacobs MR. Resistance patterns of Streptococcus pneumoniae from carriers attending daycare centers in Southwestern Greece. Clinical Infectious Diseases 25:188-194, 1997.

193. Taba H, Kusano N. Sparfloxacin resistance in clinical isolates of Streptococcus pneumoniae. Involvement of multiple mutations in gyrA and parC genes. Antimicrobial Agents Chemotherapy 42:2193-2196, 1998.

194. Tan TQ, Schutze GE, Mason Jr EO, Kaplan SL. Antibiotic therapy and acute outcome of meningitis due to Streptococcus pneumoniae considered intermediately susceptible to broad spectrum cephalosporins. Antimicrobial Agents and Chemotherapy 38:918-923, 1994.

195. Teixeira LA, Resende CA, Ormonde LR, Rosenbaum $\mathrm{R}$, Figueiredo MAS, Lencastre $\mathrm{H}$, Tomasz A. Geographic spread of epidemic multiresistant Staphylococcus aureus clone in Brazil. Journal of Clinical Microbiology 33:2400-2404, 1995.

196. Tenover FC, Lancaster MV, Hill BC, Steward CD, Stocker AS, Hancock GA, O'Hara CM, Clarck NC, Hiramatsu K. Characterization of staphylococci with reduced susceptibilities to vancomycin and other glycopeptides. Journal of Clinical Microbiology 36:10201027, 1998.

197. Thomson KS, Chartrand AS, Sanders CC, Block SL. In-vitro activity of levofloxacin against Streptococcus pneumoniae with various levels of penicillin resistance. Journal of Antimicrobial Chemotherapy 43(supl C):1519, 1999. 
198. Tomasz A. Multiple-antibiotic-resistant pathogenic bacteria. New England Journal of Medicine 330:12471251, 1994.

199. Tomasz A. Antibiotic resistance in Streptococcus pneumoniae. Clinical Infectious Diseases 24(supl 1):S85-S88, 1997.

200. Trabulsi LR. Aspectos médicos da resistência bacteriana a drogas. Revista de Microbiologia (São Paulo) (supl espec): 1-30, 1973.

201. Tremblay C, Bourgault, St.Antoine P. Meningitis in a Canadian adult due to high-level penicillin resistant, cefotaxime-intermediate Streptococcus pneumoniae. Canadian Journal of Infectious Diseases 7:205-207, 1996.

202. Ubukata K, Yamashita N, Konno M. Occurrence of a B-lactam-inducible penicillin-binding protein in methicillin-resistant staphylococci. Antimicrobial Agents and Chemotherapy 27:851-857, 1985.

203. Uttley AHC, Collins $\mathrm{CH}$, Naidoo J, George RC. Vancomycin-resistant enterococci. Lancet 1:57, 1988.

204. Vilins M, Valdetaro F, Blecher S, Pignatari AC, Medeiros EA, Zanella RC, Brandileone MCC, Salomão RC. Prevalência de Enterococcus resitente à vancomicina (VRE) em hospital de grande porte na região metropolitana de São Paulo. Brazilian Journal of Infectious Diseases 3(supl 2):S24, 1999.

205. Waldvogel FA. New resistance in Staphylococcus aureus. New England Journal of Medicine 340:556-557, 1999.

206. Wenzel RP, Edmond MB. Vancomycin-resistant Staphylococcus aureus: infection control considerations. Clinical Infectious Diseases 27:245-251, 1998.
207. Wlliams RJ, Heyman DL. Containment of antibiotic resistance. Science 279:1153-1154, 1998.

208. Witte W. Medical consequences of antibiotic use in agriculture. Science 279:996-997, 1998.

209. Woodford N. Glycopeptide-resistant enterococci: a decade of experience. Jounal of Medical Microbiology 47:849-862, 1998.

210. Woodford N, Johnson AP, Morrison D, Speller DCE. Current perspectives on glycopeptide resistance. Clinical Microbiology Review 8:585-615, 1995.

211. World Health Organization Scientific Group. Antimicrobial resistance. Bulletin of World Health Organization 61:383-394, 1983.

212. Zanella RC, Darini ALC, Brandileone MCC, Bokermann S, Almeida SCG, Valdetaro F, Salomão R, Viling M, Woodford N, Pignatari AC. Análise molecular de Enterococcus e dos seus Elementos VanA que mediam resistência a vancomicina isolados na Casa de Saúde Santa Marcelina - SP, em 1998. Brazilian Journal of Infectious Diseases 3(supl 2):S7, 1999.

213. Zanella RC, Valdetaro F, Lovgren M, Tyrrel GJ, Bokermann S, Almeida SCG, Vieira VSD, Brandileone MCC. First confirmed case of a vancomycin-resitant Enterococcus faecium with vanA phenotype from Brazil: isolation from a meningitis case in São Paulo. Microbial Drug Resistance 5:159-162, 1999.

214. Zervos MJ, Kauffman CA, Therasse, PM, Bergman AG, Kikesell TS, Schaberg DR. Nosocomial infection by gentamicin-resistant Streptococcus faecalis. Annals of Internal Medicine 106:686-691, 1987.

215. Zuliani ME, Trabulsi LR. Resistência microbiana a drogas. Ars Curandi 5:50-72, 1972. 